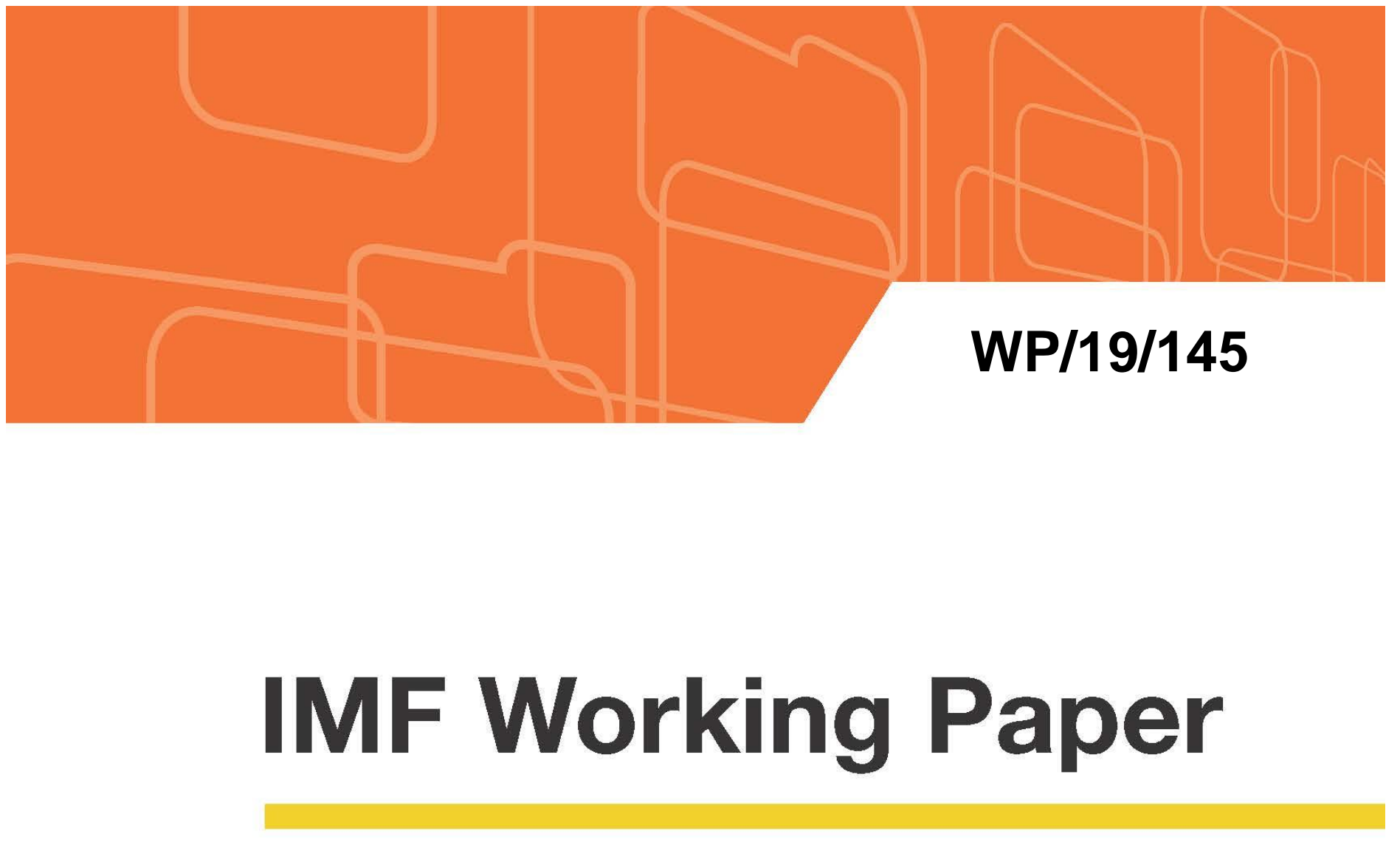

\title{
Climate Disaster Risks - Empirics and a Multi-Phase Dynamic Model
}

\author{
by Stefan Mittnik, Willi Semmler, and Alexander Haider
}

IMF Working Papers describe research in progress by the author(s) and are published to elicit comments and to encourage debate. The views expressed in IMF Working Papers are those of the author(s) and do not necessarily represent the views of the IMF, its Executive Board, or IMF management. 


\title{
IMF Working Paper
}

Research Department

\section{Climate Disaster Risks - Empirics and a Multi-Phase Dynamic Model $^{*}$}

\author{
Prepared by Stefan Mittnik, Willi Semmler, and Alexander Haider \\ Authorized for distribution by Chris Papageorgiou
}

July 2019

\section{IMF Working Papers describe research in progress by the author(s) and are published to elicit comments and to encourage debate. The views expressed in IMF Working Papers are those of the author(s) and do not necessarily represent the views of the IMF, its Executive Board, or IMF management.}

\begin{abstract}
Recent research in financial economics has shown that rare large disasters have the potential to disrupt financial sectors via the destruction of capital stocks and jumps in risk premia. These disruptions often entail negative feedback e ects on the macroecon-omy. Research on disaster risks has also actively been pursued in the macroeconomic models of climate change. Our paper uses insights from the former work to study disaster risks in the macroeconomics of climate change and to spell out policy needs. Empirically the link between carbon dioxide emission and the frequency of climate re-lated disaster is investigated using cross-sectional and panel data. The modeling part then uses a multi-phase dynamic macro model to explore this causal nexus and the $\mathrm{e}^{\cdot}$ ects of rare large disasters resulting in capital losses and rising risk premia. Our proposed multi-phase dynamic model, incorporating climate-related disaster shocks and their aftermath as one phase, is suitable for studying mitigation and adaptation policies.
\end{abstract}

JEL Classification Numbers: C61, Q54, Q58, H5

Keywords: climate economics, disaster risk, macro feedbacks, multi-phase macro model, monetary and financial policies, environmental economics

Author's E-Mail Address: SemmlerW @ newschool.edu

\footnotetext{
* The basic structure of this paper was developed while Willi Semmler was a visiting scholar at the IMF Research Department. The authors would like to thank Chris Papageorgiou, Prakash Loungani and their colleagues for many helpful insights and comments.
} 


\section{Contents}

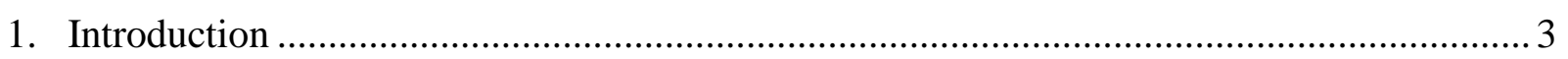

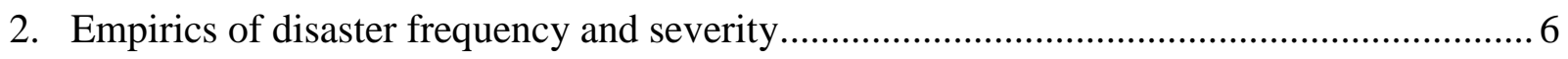

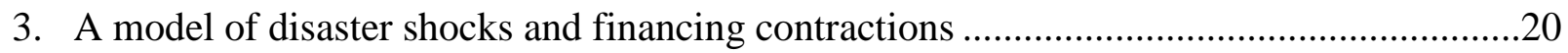

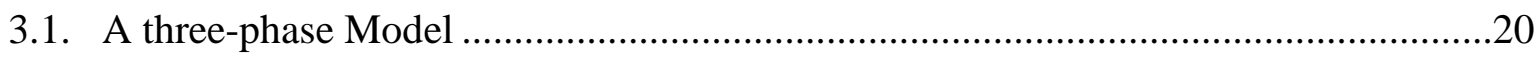

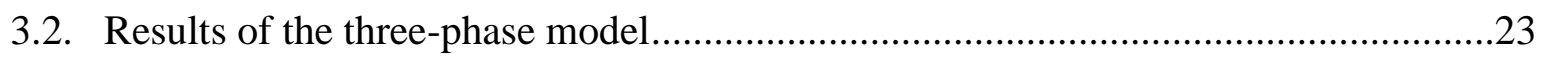

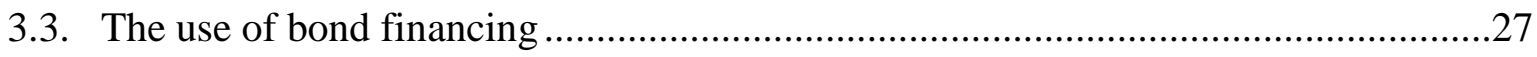

4. Other policies for the green transition and disaster management …...................................32

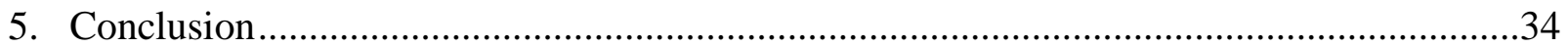

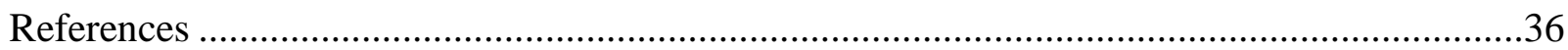

\section{Appendix}

A.1. Fixed effects Coefficients for Panel Model ..................................................................

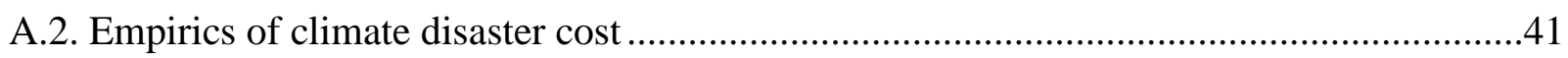

A.3. Base line macro dynamic model...................................................................................

\section{Tables}

1. Poisson Regression with robust standard errors by region..................................................17

2. Disaster frequency in relation to $\mathrm{CO}_{2}$ concentration in the atmosphere .............................18

3. Change in disaster frequency in relation to $\mathrm{CO}_{2}$ concentration in the atmosphere ...............19

4. Parameters defining weak and strong shocks for the three time periods .............................23

\section{Figures}

1. Frequency of droughts between 1976 and 2017 by region ................................................

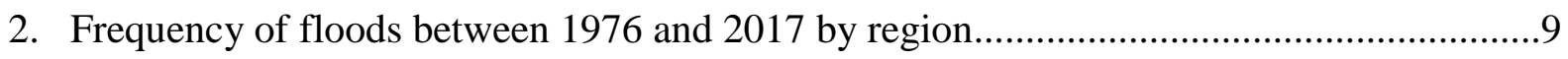

3. Frequency of landslides between 1976 and 2017 by region ..............................................10

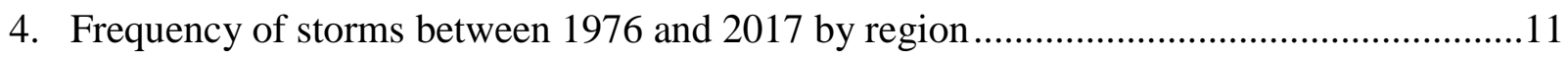

5. Frequency of wildfires between 1976 and 2017 by region ................................................12

6. Frequency of extreme temperatures between 1976 and 2017 by region ...............................13

7. Frequency of climate related disaster (total) between 1976 and 2017 by region ..................14

8. Annual CO2 mole fraction increase (in parts per million) from 1976 until 2017 .................15

9. Government debt in a three-phase model, red: weak shock, blue: strong shock...................24

10. Government capital in a three-phase model, red: weak shock, blue: strong shock ..............25

11. Private capital stock in a three-phase model; red: weak shock, blue: strong shock .............26

12. Fossil fuel consumption in a 3-stage model, red: weak shock, blue: strong shock ..............27

13. Path of consumption in a three-stage model; red: weak shock, blue: strong shock .............28

14. Carbon Tax Policy and Issuance of Climate Bounds ............................................................31 


\section{Introduction}

Much recent research in the economics of climate change has utilized modern statistical and econometric methods to study the links between GDP growth, greenhouse gas (GHG) emission, global warming, and climate-related disasters. Additional research, for example by the IMF (2017), has shown that in particular low income countries and regions will be vulnerable to climate related disasters. At the same time they have only little economic and financial capacity to adapt. ${ }^{1}$

Similar research on large disaster risk has been undertaken in financial economics, especially since the financial crisis 2007/9 and the subsequent world-wide recession. In particular the destruction of capital stocks and jumps in risk premia after rare large economic and financial crisis are investigated in great detail. For example, Rietz (1988) studies rare market crashes and their effect on equity risk premia. Barro (2006) uses as disaster measure the decline of GDP growth, while Barro and Ursua (2008) and Gabaix (2011) investigate the decline of consumption spending due to large disaster. Barro (2006) and Gourio (2012) measure disasters in terms of loss in total factor productivity (TFP) and declines in the capital stock. The latter is formally introduced in these models as a sudden increase in the capital depreciation rate. The proportionality of output and capital losses can then be demonstrated in an "AK" growth model (Barro, 2006). Usually strong persistence of disaster shocks is assumed which results in long run effects of such shocks, see Catalano et al. (2018). Recent literature frames this issue in the context of DSGE models. Numerical solution methods for solving DSGE models with disasters - by measuring disasters as physical capital and output losses - have been developed by Fernandez-Villaverde and Levintal (2016). Disasters are then mainly modeled as highly persistent shocks with mean reversion after the event.

Economic and financial studies on rare large crashes were undertaken with the intention of demonstrating the effect of financial disasters on asset prices and returns. Researchers intended to show that the equity premium puzzle and volatile discount rates can be resolved with reference to rare large disasters.

There is also a significant strand of literature on climate disasters focusing on physical destruction of countries and regions. The focus has been on destruction caused by rare large disasters and on slow temperature increases and its negative effects on long-run productivity (IMF, 2017). Particularly important is the study by Burke et al. (2015) which explores

\footnotetext{
${ }^{1}$ See Bernard and Semmler (2015); see also IMF (2017) and Burke et al. (2015).
} 
the non-linear effects of climate change based on the work of Gumbel (1958). A related study is given by Cantelmo et al. (2017), where climate disaster losses are introduced in a macroeconomic model as capital losses, implying some long-run persistent effect. Here fiscal p olicy is s uggested for d isaster $\mathrm{m}$ anagement. The r ole of $\mathrm{p}$ ublic c apital for disaster management is stressed by Adam and Bevan (2014) and Bevan and Adam (2016). The effects of rare large disasters on risk premia, credit cost, credit spread and credit constraints will be analyzed in the context of our model. ${ }^{2}$ In addition, fiscal, monetary a nd financial policy interventions will be introduced to study disaster management approaches in detail. To the best of our knowledge this has not been done in climate disaster studies.

Although the causes of disaster risk arising from climate change differ from disaster risk originating in large financial crises, the effects may be s imilar. In both cases actual output may recover in the short run, but potential capacity is reduced, while physical, public and human capital will be destroyed, causing persistently low growth in the future. This effect is often referred to as a hysteresis effect of shocks. In this context some authors suggest to work with multiple equilibria models, allowing for trapping probabilities and poverty traps after the disaster event, see Kovacevic and Pflug (2011). Moreover, due to large temporary shocks and capital losses, risk premia and borrowing cost for credit are likely to rise steeply. Increased credit constraints will be the result and the affected country or region may face a trapping probability allowing for a very slow recovery only.

Both research areas are concerned with similar policies - policies addressing the mitigation and reduction of long run causes of disasters and how to deal with after-the-event situations. In terms of policies, balancing the competing, yet often complementary, needs of climate change, mitigation and adaptation becomes a complex problem. Different policies may be substitutes in the short run, but complements in the long run: active mitigation policies may reduce the risk of large disasters, but they are expensive and their benefits may only accrue in the long run. At the same time adaptation policies may solve short-term problems in a more satisfactory way, but their costs increase strongly if mitigation policies remain underfunded.

We address these important policy issues by presenting some empirical results first. We explore the link between rising carbon dioxide levels in the atmosphere and the frequency of climate disasters in seven regions: East Asia and Pacific (EAS), Europe and Central Asia (ECS), Latin America and the Caribbean (LCN), Middle East and North Africa (MEA),

\footnotetext{
${ }^{2}$ Relevant literature on monetary policy and climate change are McKibbin et al. (2017) and Fratzscher et al. (2017).
} 
North America (NAC), South Asia (SAS), and Sub-Saharan Africa (SSF). We also present a modeling framework on the occurrence of large disasters in a multi-phase dynamic macro model. In this context we discuss the role of monetary and financial policies in dealing with those disasters.

In doing so we build on a macro model developed by Bonen et al. (2016), Maurer et al. (2018) and Semmler et al. (2018) which allows for studying the issue of large climaterelated disaster shocks and climate change policies. Our model explicitly solves for fiscal and financial resources to deal with trade-offs of mitigation and adaptation p olicies. These policies are operationalized as time varying shares of public capital in support of carbonneutral productivity-enhancing infrastructure, mitigation and adaptation capital. In those model variants carbon intensity of the energy resources is not taken as a side-product of production. Instead we endogenize carbon intensity by linking emissions to the extraction of a non-renewable resource (e.g., fossils fuels), and show how renewable energy can be phased in through public-sector investment, thereby phasing out fossil energy. This allows us to combine contemporary 'social cost of carbon' (SCC) approaches, as used in an Integrated Assessment Model (IAM), with the resource extraction models of Hotelling (1931) and Pindyck (1978) and extended by Maurer and Semmler (2011). Moreover, the macro model presented here extends the recent modeling advances that allow agents to respond to climate change by combining mitigation and adaptation actions, see Ingham et al. (2007), where mitigation might reduce vulnerability. The solution method of solving the multi-phase model is presented in Maurer et al. (2018).

Climate finance p olicy - we m ainly explore the issue of s caling u p c limate investment through bond issuance - suggests scaling up the process of initiating bond financing at a certain stage of climate policies and then reducing accumulated debt by an income tax in a later stage. Therefore we propose combining in a more general way fiscal, financial, and monetary policies for tackling climate change. Our approach gives rise to a three-phase model, first $\mathrm{u}$ sing $\mathrm{t}$ axation a nd fi scal to ols, fo llowed by sc aling up in vestments by bond financing, concluded by a final stage of bond repayment for debt re duction. A single stage model, described in appendix A.3, is contrasted with such a multi-phase model. We also explore the economic and financial impacts of large disasters and study the impact of fiscal, financial and monetary policy tools on mitigation as well as on adaptation.

The remainder of the paper is organized as follows. Section 2 presents some empirics on the causal link between rising carbon dioxide levels - to a large extent due to economic expansion - and climate risks, measured as the number of climate disasters for a given 
year (disaster frequency). Section 3 introduces the multi-phase dynamic decision problem and applies it to a three-phase macro model with phase-specific c limate d isasters, fiscal, monetary and financial $\mathrm{p}$ olicies. $\mathrm{S}$ ection $4 \mathrm{p}$ rovides $\mathrm{s}$ ome $\mathrm{d}$ iscussion o $\mathrm{n}$ b roader policies including fiscal and monetary policy tools of mitigation and a daptation $\mathrm{p}$ olicies. Section 5 concludes.

\section{Empirics of disaster frequency and severity}

We study the frequency of climate disasters within regions in this section. The empirics of climate disasters will lay the groundwork for the theoretical model of section 3 .

There are numerous disaster studies in the economics of climate change. Those studies have looked at climate disasters and the physical destruction they cause for region and country groups, resulting from rare extreme weather events as well as from gradual temperature increases. Negative impacts of gradual temperature increases on productivity are studied by IMF (2017). Noteworthy is the study by Burke et al. (2015) which relates to the work of Gumbel $(1935,1958)$ on extreme value theory and the non-linear effects from climate change.

A related study is given by Cantelmo et al. (2017), which represents one of the few papers on the macroeconomics of climate disasters where losses are measured as capital loss, implying some long-run persistent effect. Similar to our work, the role of public capital for disaster management is stressed in Adam and Bevan (2014) and Bevan and Adam (2016). Moreover, there are the studies by Hochrainer-Stigler et al. (2014) and Kovacevic and Pflug (2011) which include considerations on disaster insurance and trapping probabilities. Our empirical approach is closely related to Thomas et al. (2013) and Thomas and Lopez (2015). They study the increase of climate-related disasters and anthropogenic climate change based on panel models for count data and find a positive relationship between disaster frequency and disaster risk factors caused by man-made GHG emission. More specific studies, for example on flooding disasters in Bangladesh, are undertaken, by Hochrainer et al. (2009).

It is worth contrasting the way probability theory is defining (exogenous) $r$ are large events with our set up. Studies based on a probabilistic approach weigh the (low) probability of large disaster events with the size of the losses. In our context, however, we see disaster probabilities being driven endogenously by rising vulnerabilities due to a rise in $\mathrm{CO}_{2}$ emission. Our empirical approach mainly builds on the EMDAT database provided by 
the Centre for Research on the Epidemiology of Disasters (CRED). ${ }^{3}$ The database provides observations on different kinds of natural and technological disasters. Following Coronese et al. (2018) we identify six types of natural disasters which are related to climate change: floods, d roughts, landslides, wildfires, st orms, an d ex treme temperature.

As disaster data is known for being subject to several data issues, such as underreporting for disasters in the more distant past (Guha-Sapir et al., 2013), data preparation becomes a vital issue. We only use data starting in 1976 to deal with the most severe data distortions. In addition, we focus on the number of disasters/disaster frequency. ${ }^{4}$ Our dependent variable is constructed by summing up the number of climate related disaster for the six categories mentioned above for a given year and region. ${ }^{5}$

Before studying the relationship between $\mathrm{CO}_{2}$ emission and climate related disasters in more detail, we present some stylized facts based on the EMDAT database. Figures 1-7 show the number of climate related disasters, as defined above, for the time period between 1976 and 2017.

Figure 1 depicts the number of droughts for each region in the database between 1976 and 2017. No strong trending behavior is observed. For the Middle East and North Africa, North America, and South Asia the occurrence of droughts is limited for the given time horizon. In fact, the EMDAT database does not report any droughts for the Middle East and North Africa since 2010. For the other regions the pattern is volatile, especially for Sub-Saharan Africa were the number of droughts varies strongly over the sample period. East Asia and Latin America and the Caribbean also show very volatile patterns. Europe and Central Asia, on the other hand, do not follow this pattern. A large spike is given for this region in 2000 when 10 droughts were reported. The second largest value for Europe and Central Asia are given in 2004 and 2017 with only 4 occurrences each.

\footnotetext{
shttps://www.emdat.be/; EMDAT reports events which cause at least 10 deaths, affect at least 100 people, or prompt a declaration of a state of emergency or a call for international assistance as a disaster.

${ }^{4}$ Data on real climate disaster cost is provided in appendix A.2. Figures 15 and 16 show severe data issues for climate disaster cost. We regard the number of climate disasters as the more reliable indicator and therefore focus on it in this section.

${ }^{5}$ In our empirical analysis we focus on the seven regions identified by the World Bank Atlas method: https://datahelpdesk.worldbank.org/knowledgebase/articles/ 906519-world-bank-country-and-lending-groups
} 
Figure 1: Frequency of droughts between 1976 and 2017 by region. Regional classification follows the World Bank classification system. Source: Authors' estimates based on data from EMDAT.

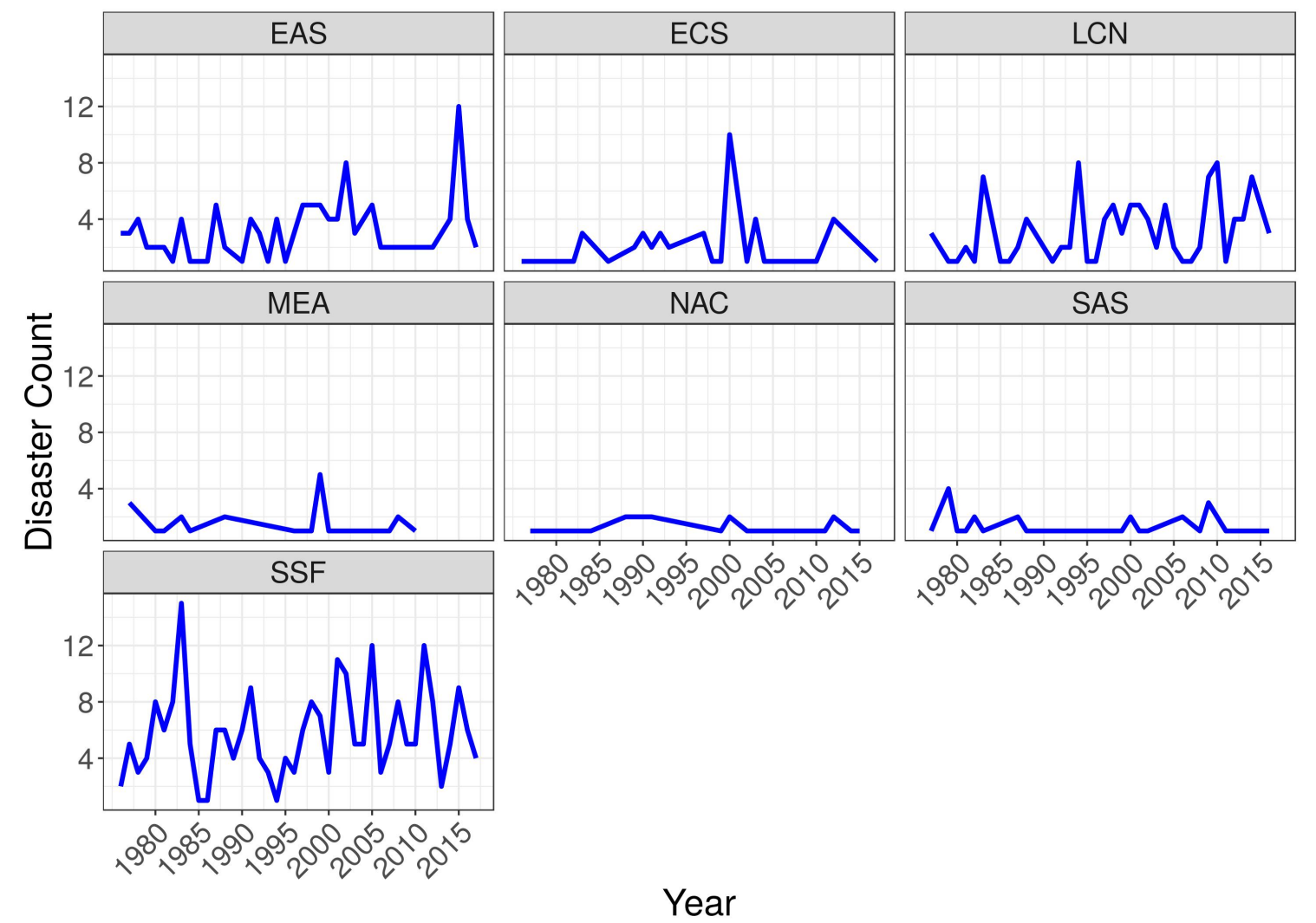

In contrast to droughts, an upward trending behavior can be observed for floods for almost every region with the exceptions of North America and the Middle East and North Africa. These patterns are shown in Figure 2. A strong increases in flooding disasters is very pronounced for East Asia and for Sub-Saharan Africa. However, Sub-Saharan Africa, East Asia, South Asia, and Europe and Central Asia show a downward pattern for the most recent years. The number of floods reached their maximum in Europe and Central A sia in 2005, while the maximum was obtained ins Sub-Saharan Africa in 2007. For East Asia the highest value was realized in 2006 and in South Asia in 2005. 
Figure 2: Frequency of floods between 1976 and 2017 by region. Regional classification follows the World Bank classification system. Source: Authors' estimates based on data from EMDAT.
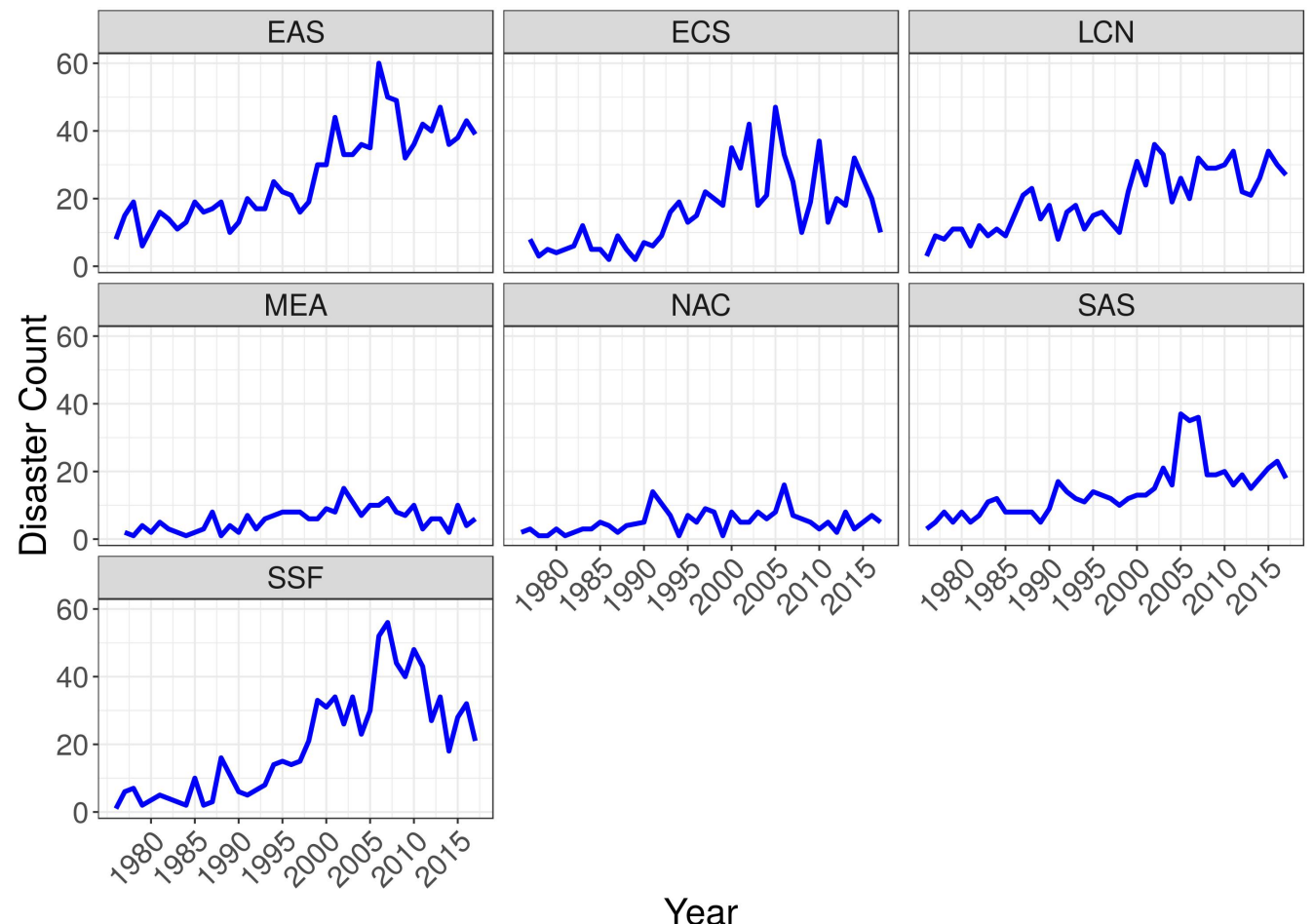

The next graph (Figure 3) shows the number of landslides for our seven regions between 1976 and 2017. The number of landslides per year is flat in North America and in the Middle East and North Africa where the number of observations per year never surpasses a value of one. In East Asia we observe an upward trend but, as before, there has been a decreasing number of reported incidents in the most recent past. In fact, the highest reported value is found in 2013 when 13 landslides were reported. For Europe and Central Asia and Latin America and the Caribbean no discernible pattern is given. The number of landslides per year is volatile but there is no trend. A small upward trend in landslides may be observed in South Asia. Here the year-on-year change is very large again. For Sub-Saharan Africa the data suggest an increasing number of landslides per year for the region since the late 1990s. 
Figure 3: Frequency of landslides between 1976 and 2017 by region. Regional classification follows the World Bank classification system. Source: Authors' estimates based on data from EMDAT.

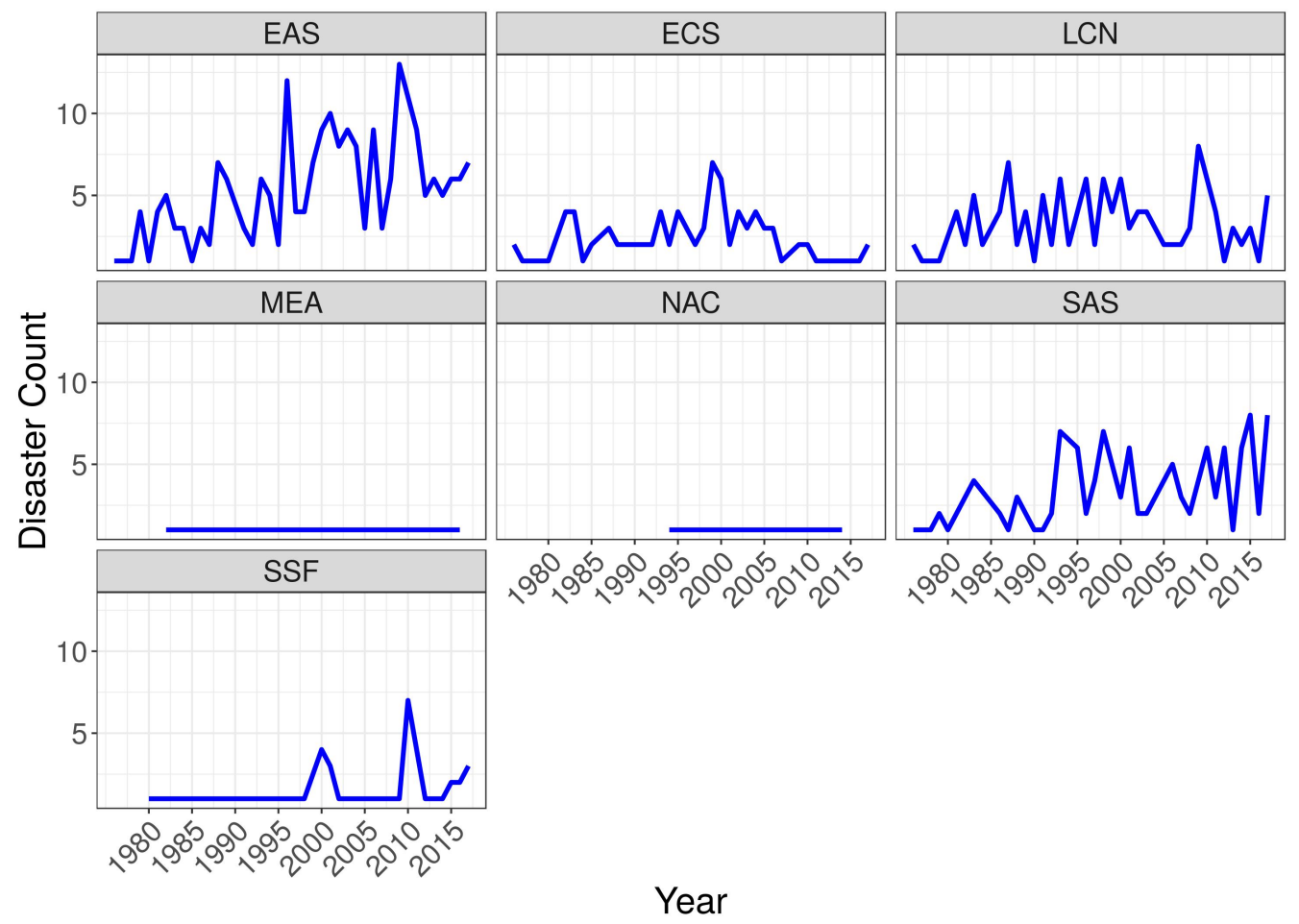

Figure 4 illustrates an upward trend of storms in East Asia since the 1970s. A similar pattern, although not as strong as in East Asia can be observed for Latin America and the Caribbean, North America, and Sub-Saharan Africa. On the other hand, no upward trend is observed in Europe and Central Asia, the Middle East and North Africa and Sourth Asia. In Europe and Central Asia a large spike is given in 1990 when 66 storms were recorded. The second largest value is given in 2005 with (only) 26 reported incidents. 
Figure 4: Frequency of storms between 1976 and 2017 by region. Regional classification follows the World Bank classification system. Source: Authors' estimates based on data from EMDAT.

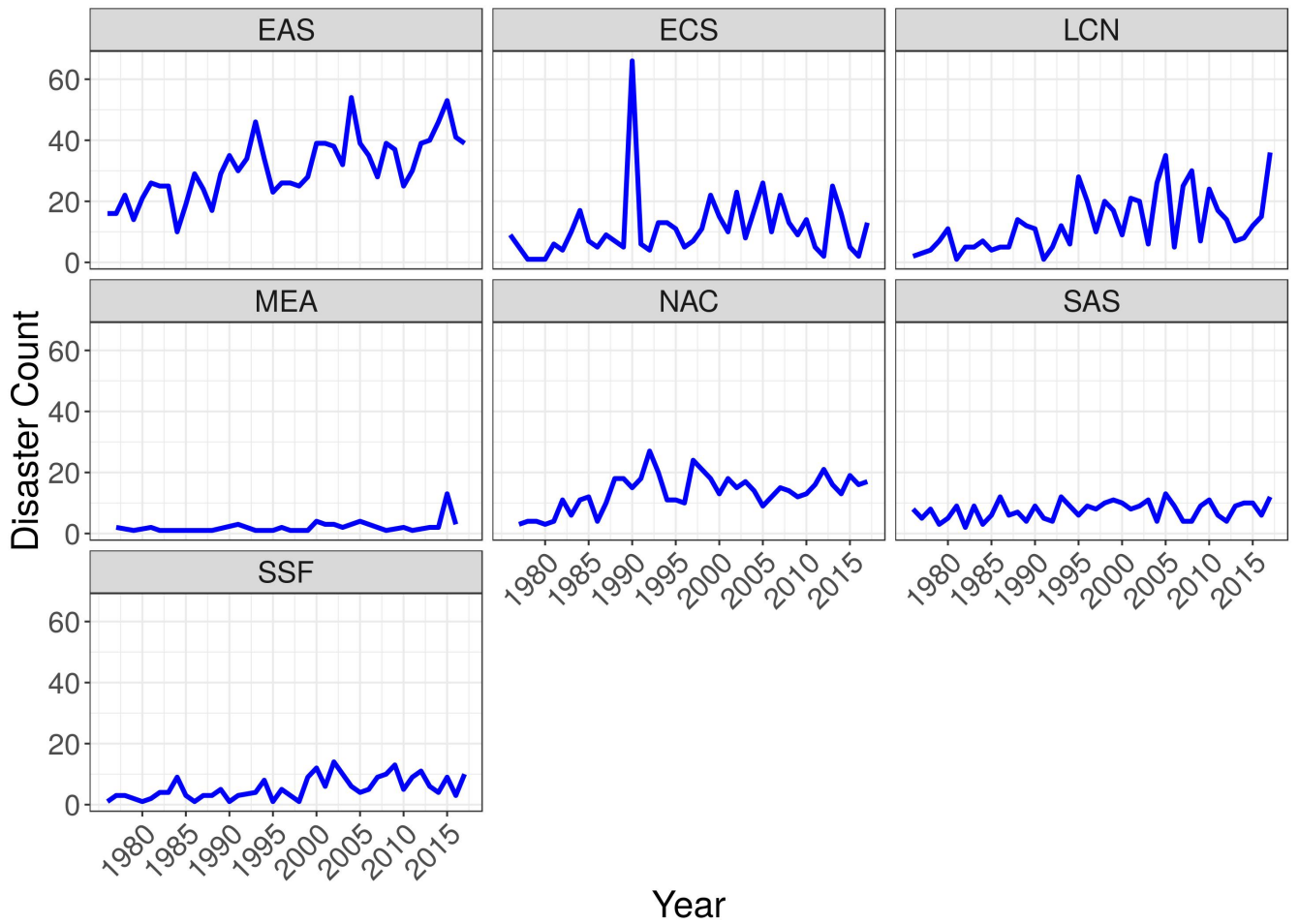

The number of wildfires is d epicted in F igure 5 . W ildfires ar e ve ry li mited for most regions. The maximum value for South Asia is attained in 1999 with 4 wildfires. In the Middle East and North Africa a similar pattern can be observed. The number of wildfires is very small. Sub-Saharan Africa also reports very small numbers. The number of wildfires is considerable higher in Europe and Central Asia where a maximum of 16 is reached in 2000. In North America the largest value is observed in 2002 with 9 wildfires. For East Asia the number of wildfires is again limited although it is higher than for the Middle East and North Africa, Latin America and the Caribbean and in Sub-Saharan Africa. Finally, the number of wildfires is also very limited in Latin America and the Caribbean. 
Figure 5: Frequency of wildfires between 1976 and 2017 by region. Regional classification follows the World Bank classification system. Source: Authors' estimates based on data from EMDAT.
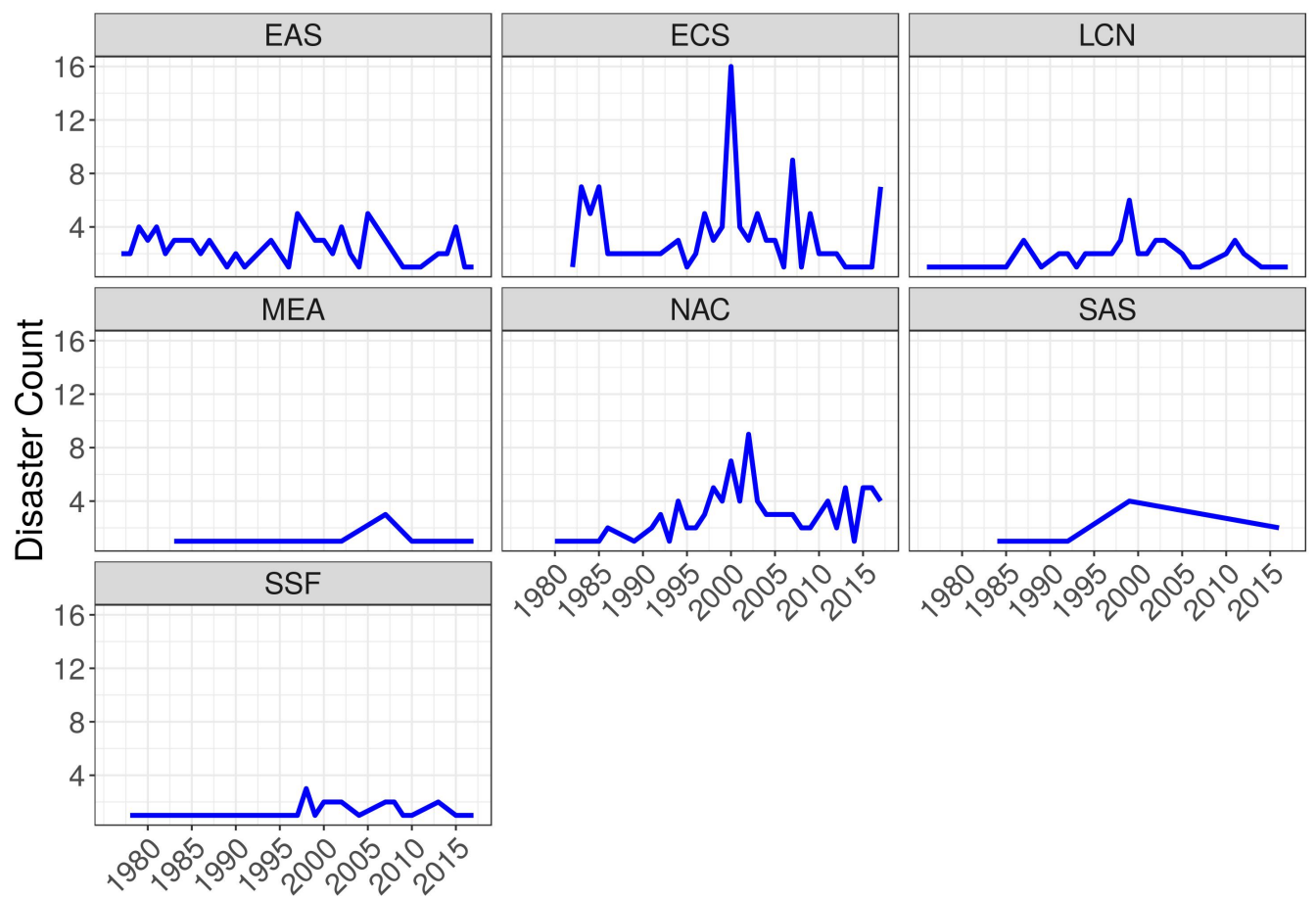

\section{Year}

Figure 6 reports the number of observations on extreme temperature events. As can be seen from the figure the number of observations is very limited for all regions but Europe and Central Asia. In fact, the number of observations for this disaster category is below 10 for each year for all regions but Europe and Central Asia. For Europe and Central Asia an increase in the number of observations can be observe in Figure 6, although the pattern is rather erratic. Still, 43 extreme temperature events were reported in Europe and Central Asia in 2012. The second highest value was attained in 2005 with 22 reported incidents. 
Figure 6: Frequency of extreme temperatures between 1976 and 2017 by region. Regional classification follows the World Bank classification system. Source: Authors' estimates based on data from EMDAT.

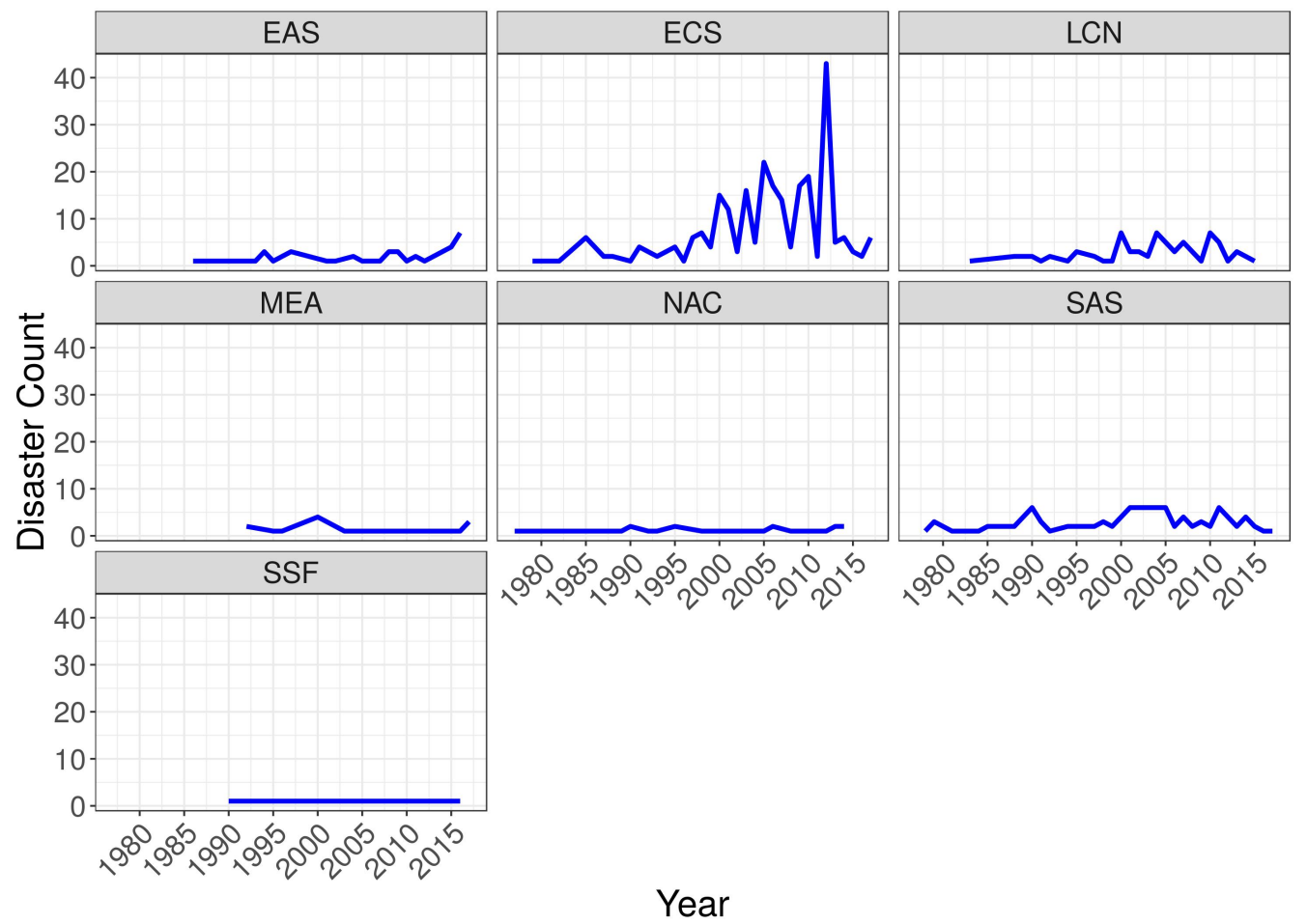

As mentioned above, the six categories just described are summed up for every year and region and classified as climate related disasters $\mathrm{h}$ ere. The results are shown in Figure 7 for our seven regions. We observe a clear upward trend for most regions. In Europe and Central Asia an upward trend is clearly given up until 2005. In the following years the number of observations decreased somewhat. On the other hand, the trend for East Asia and Latin America and the Caribbean is increasing over the entire sample period. A similar pattern is observed for Sub-Saharan Africa. Here a small decrease for the most recent years becomes visible again. The number of disasters decreases from an all-time high of 74 observations in 2007 to 39 climate related disaster in 2017. In contrast to theses patterns, the trend in the Middle East and North Africa and in North America is not as pronounced, although we observe a positive trend in North America. Finally, in South Asia an upward trend is observed as well. 
Figure 7: Frequency of climate related disaster (total) between 1976 and 2017 by region. Regional classification follows the World Bank classification system. Source: Authors' estimates based on data from EMDAT.

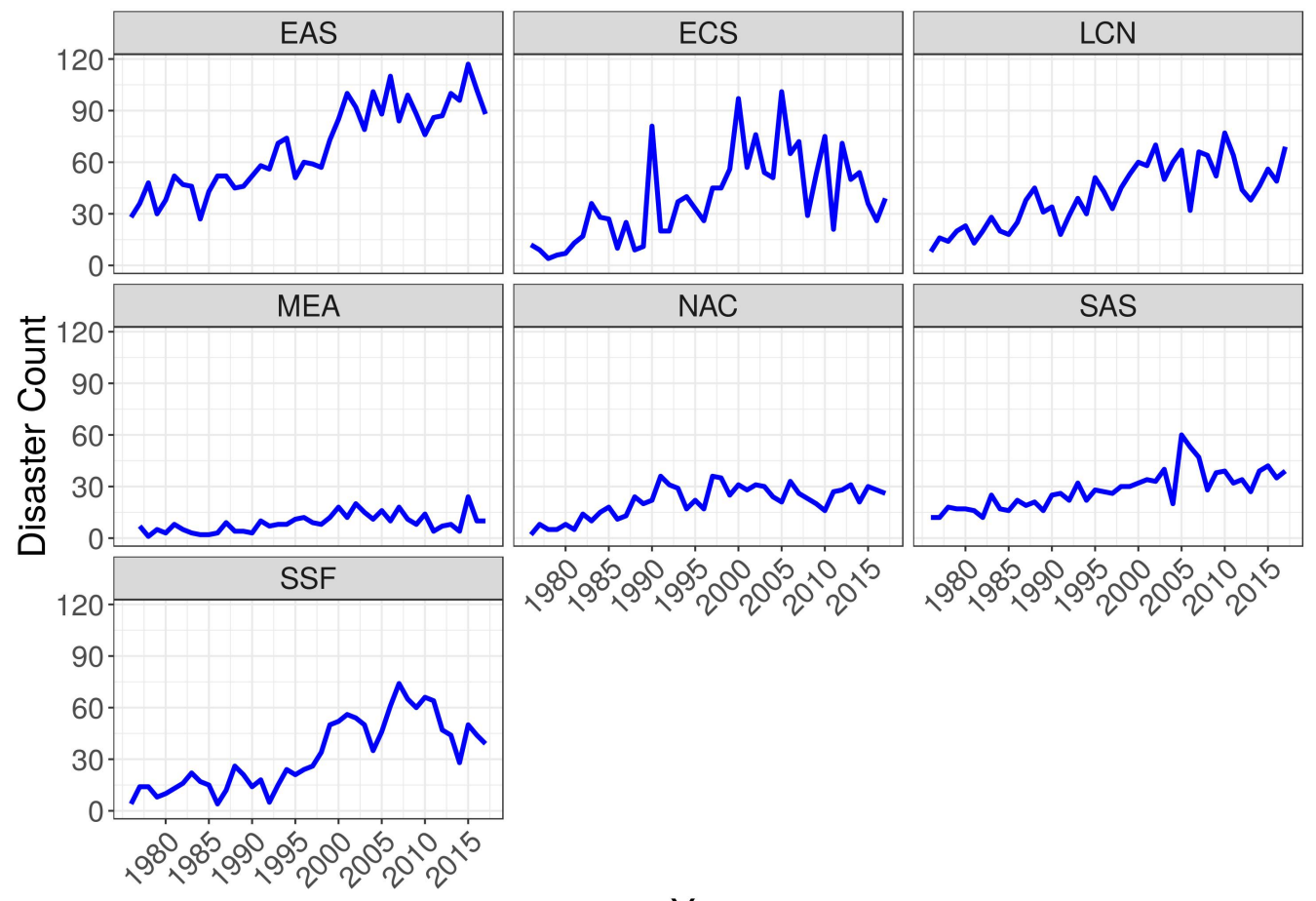

Year

Lastly, Figure 8 shows the annual increase in carbon dioxide in the atmosphere expressed as a mole fraction in dry air. The data is provided by the Mauna Loa Observatory and shows the growth (first differences) of the collected data between 1976 and 2017. Data collected at the Mauna Loa Observatory is intended to represent carbon dioxide levels in the atmosphere for the northern hemisphere. However, the annual increase based on the Mauna Loa data is very similar to the global annual increase and is therefore used for the southern hemisphere as well in this study. ${ }^{6}$ In the following empirical analysis we will focus on the data shown in Figure 8 and its relationship with the total number of climate related disaster, represented by Figure 7.

\footnotetext{
${ }^{6}$ See https://www.esrl.noaa.gov/gmd/ccgg/trends/gr.html for more details on the data.
} 
Figure 8: Annual $\mathrm{CO}_{2}$ mole fraction increase (in parts per million) from 1976 until 2017. The data is provided by the Mauna Loa Observatory.

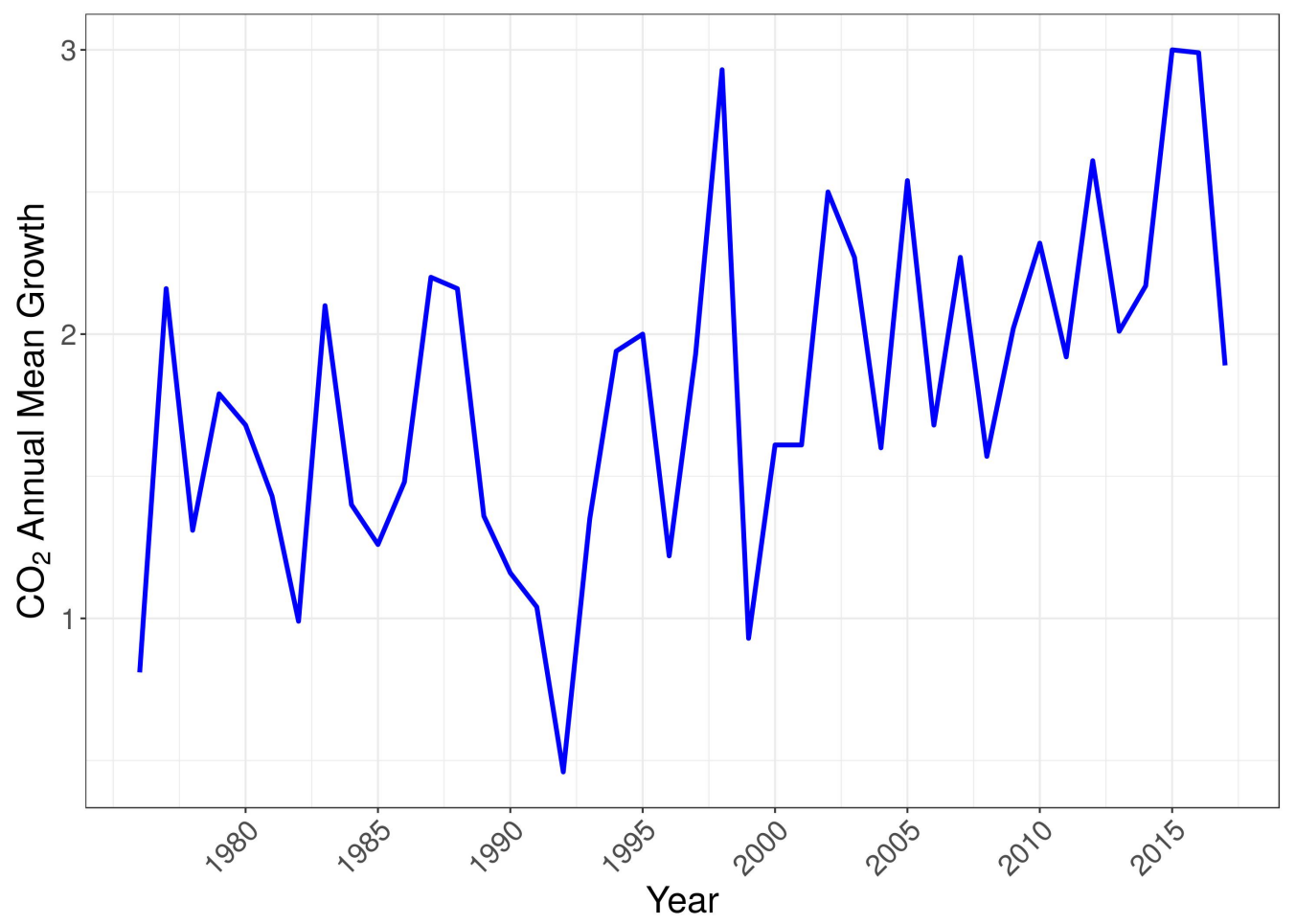

The link between GHG concentration in the atmosphere in general, and $\mathrm{CO}_{2}$ concentration in particular, and the increased frequency of natural disasters is well documented, see Thomas et al. (2013) for an overview. IPCC (2012) argue that increased GHG emission, leading to increasing concentration in the atmosphere, alters climate variables, especially temperature and precipitation levels. These changes in climate variables increase the frequency of climate-related hazards. Growth in $\mathrm{CO}_{2}$ concentration in the atmosphere therefore only represents an indirect effect on climate-related disasters. However, focusing on $\mathrm{CO}_{2}$ instead of changes in temperature and precipitation has certain merits. As Miller et al. (2014) point out, the increasing concentration of GHG (and aerosols) represents the main perturbation to the earth's climate. In addition, long-lived GHG like $\mathrm{CO}_{2}$ show only small geographic variations and can be easily measured at few sites with low levels of uncertainty. Therefore changes in $\mathrm{CO}_{2}$ concentration lend themselves to the empirical analysis in this section. In contrast, changes in surface temperature (anomalies) show high levels of geographic variation, are more volatile and affected by numerous factors, such as the El-Niño 
Southern Oscillation, solar variability, and volcanic activity (IPCC, 2013; Lean and Rind, 2008). ${ }^{7}$

In addition to the growth in $\mathrm{CO}_{2}$ concentration, we add the lagged value of disaster frequency as a regressor. We do this to take non-stationarity of our dependent variable into account. As the effects stemming from an increase in $\mathrm{CO}_{2}$ concentration may be slow moving we add the current increase and 17 lags of it to our model. However, the number of observations is limited. We therefore sum up the current increase in $\mathrm{CO}_{2}$ concentration and our 17 lags in one variable (Sum of $\mathrm{CO}_{2}$ increases in Tables 1, 2 and 3). By using current and lagged increases in $\mathrm{CO}_{2}$ from the Mauna Loa Observatory as a proxy for the global average, Sum of $\mathrm{CO}_{2}$ increases represents the sum of all $\mathrm{CO}_{2}$ added and removed from the atmosphere for a given year by human activities and natural processes. ${ }^{8}$

Table 1 shows the results of Poisson regressions for each region with robust standard errors. As can be seen from the table, the Sum of $\mathrm{CO}_{2}$ increases coefficient is positive and statistically significant for 6 out of 7 regions, with Sub-Saharan Africa being the exception.

In Table 2 we report the results of linear fixed effects panel regressions with individual effects (i.e. regional effects) to control for contemporary regional change. As increases in $\mathrm{CO}_{2}$ do not vary between regions for a given year, time fixed effects cannot be applied in our panel regression. Once again we regress the number of disaster events for a given year on its lagged value and on the sum of the current and 17 most recent increases in $\mathrm{CO}_{2}$ levels in the atmosphere. Standard errors are adjusted for heteroskedasticity and (crosssectional) serial correlation (Arellano, 1987). We observe a positive influence of increases in $\mathrm{CO}_{2}$ on the frequency of natural disaster (column Complete Data-Set). ${ }^{9}$ In addition, we also estimate the same model for large disasters only (column Large Disaster Data-Set). Following Thomas and Lopez (2015) we only retain disasters which affect at least 1,000 people or lead to 100 deaths here. As can be seen from the column Large Disaster DataSet, the result of the now unbalanced panel confirms the results of the models discussed before. Although we observe the Sum of $\mathrm{CO}_{2}$ increases coefficient decrease in size in the second panel model, it remains positive and statistically significant. ${ }^{10}$

\footnotetext{
${ }^{7}$ Thomas and Lopez (2015) include average temperature deviations as a regressor in explaining the frequency of intense climatological disasters and do not find any significant effect. Atmospheric $\mathrm{CO}_{2}$ levels, on the other hand, are significant in their analysis.

${ }^{8}$ See again https://www.esrl.noaa.gov/gmd/ccgg/trends/gr.html for more details.

${ }^{9}$ Similar results were obtained in a GLM panel model based on a Poisson and a negative binomial model. The results are not reported here.

${ }^{10}$ Results on the fixed effects coefficients can be found in the appendix.
} 


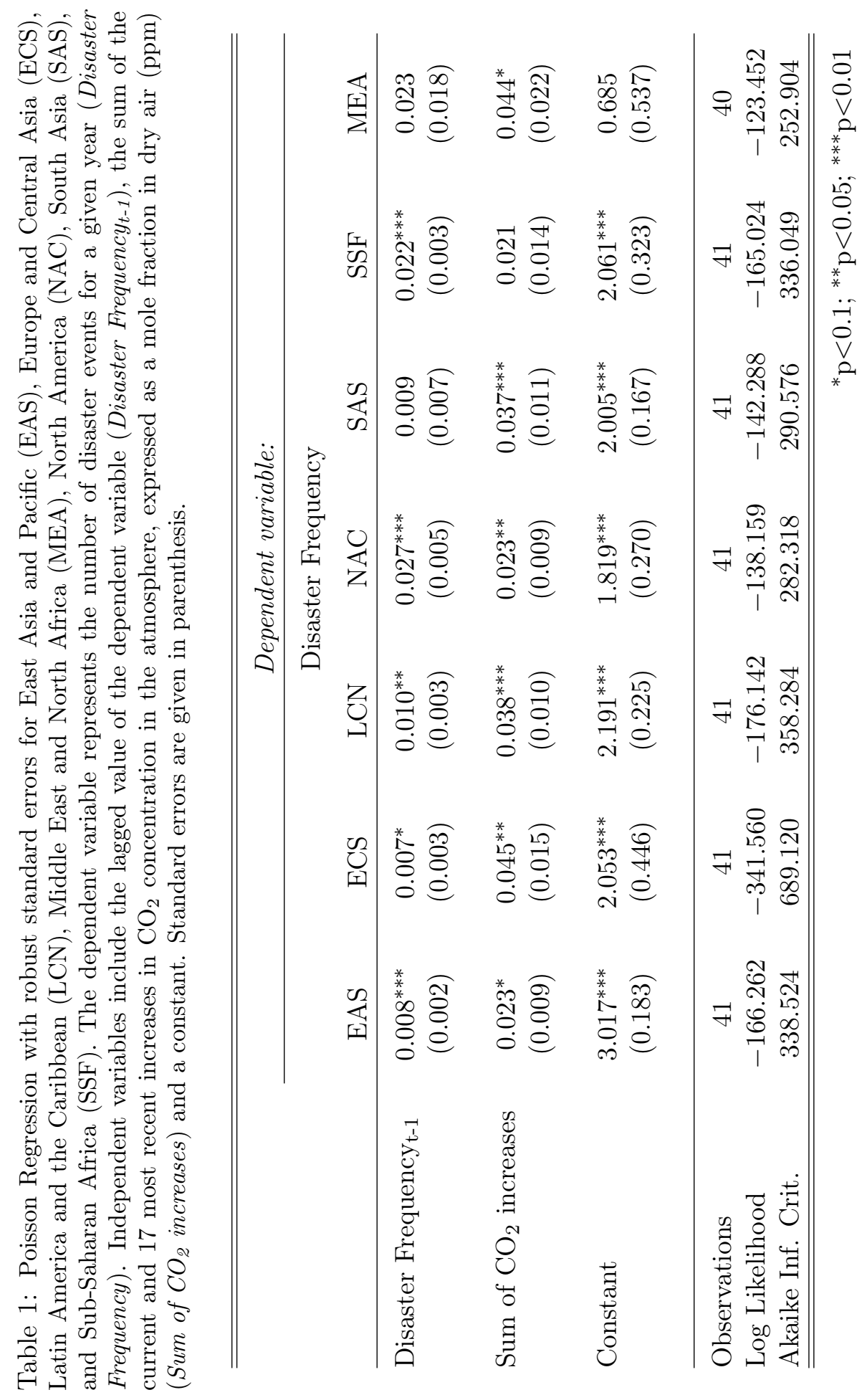


Table 2: Fixed effects Panel with heteroskedasticity and serial correlation robust standard errors. Dependent variable represents the number of disaster events for a given year (Disaster Frequency). Independent variables include the lagged value of dependent variable (Disaster Frequencyt-1) and the sum of the current and 17 most recent increases in $\mathrm{CO}_{2}$ concentration in the atmosphere, expressed as a mole fraction in dry air (ppm) (Sum of $\mathrm{CO}_{2}$ increases). Standard errors are given in parenthesis. Model Complete Data-set considers all disasters in the EMDAT database. Model Large Disasters Data-set only includes disasters with at least 1,000 affected or 100 people killed.

\begin{tabular}{lcc}
\hline \hline & \multicolumn{2}{c}{ Dependent variable: } \\
\cline { 2 - 3 } & \multicolumn{2}{c}{ Disaster Frequency } \\
& Complete Data-set & Large Disasters Data-set \\
\hline Disaster Frequencyt-1 & $0.517^{* * *}$ & $0.618^{* * *}$ \\
& $(0.071)$ & $(0.071)$ \\
& $0.947^{* * *}$ & $0.626^{* * *}$ \\
Sum of $\mathrm{CO}_{2}$ increases & $(0.168)$ & $(0.168)$ \\
& & 277 \\
\hline Observations & 280 & 0.624 \\
$\mathrm{R}^{2}$ & 0.526 & 0.612 \\
Adjusted $\mathrm{R}^{2}$ & 0.512 & $222.036^{* * *}(\mathrm{df}=2 ; 268)$ \\
F Statistic & $150.216^{* * *}(\mathrm{df}=2 ; 271)$ & ${ }^{*} \mathrm{p}<0.1 ;{ }^{* *} \mathrm{p}<0.05 ;{ }^{* * *} \mathrm{p}<0.01$ \\
\hline \hline
\end{tabular}

Lastly, we also estimate the panel model with the change in disaster frequency as the dependent variable. The right-hand side variables do not change and are the same as in Table 2. As we are estimating a model with change in disaster frequency as the dependent variable and change in $\mathrm{CO}_{2}$ concentration, as well as the lagged value of disaster frequency as independent variables, this model mimics an error-correction model. Evidence on co-integration between disaster frequency and $\mathrm{CO}_{2}$ concentration is inconclusive for our data, but the number of observations is rather limited. The results of this estimation are reported in Table 3. Once again, we observe a positive relationship between increases in $\mathrm{CO}_{2}$ concentration in the atmosphere and (change in) the frequency of disasters. 
Table 3: Fixed effects Panel with heteroskedasticity and serial correlation robust standard errors. Dependent variable represents the first difference of the number of disaster events for a given year (Diff Disaster Frequency). Independent variables include the lagged value of dependent variable (Disaster Frequencyt-1) and the sum of the current and 17 most recent increases in $\mathrm{CO}_{2}$ concentration in the atmosphere, expressed as a mole fraction in dry air (ppm) (Sum of $\mathrm{CO}_{2}$ increases). Standard errors are given in parenthesis. Model Complete Data-set considers all disasters in the EMDAT database. Model Large Disasters Data-set only includes disasters with at least 1,000 affected or 100 people killed.

\begin{tabular}{lcc}
\hline \hline & \multicolumn{2}{c}{ Dependent variable: } \\
\cline { 2 - 3 } & \multicolumn{2}{c}{ Diff Disaster Frequency } \\
& Complete Data-set & Large Disasters Data-set \\
\hline Disaster Frequency $t$ - & $-0.483^{* * *}$ & $-0.382^{* * *}$ \\
& $(0.1047)$ & $(0.0713)$ \\
Sum of $\mathrm{CO}_{2}$ increases & $0.947^{* * *}$ & $0.627^{* * *}$ \\
& $(0.2732)$ & $(0.1677)$ \\
\hline Observations & & 277 \\
$\mathrm{R}^{2}$ & 280 & 0.190 \\
Adjusted $\mathrm{R}^{2}$ & 0.242 & 0.166 \\
F Statistic & 0.219 & $31.395^{* * *}(\mathrm{df}=2 ; 268)$ \\
\hline \hline \multirow{2}{*}{ Note: } & $43.215^{* * *}(\mathrm{df}=2 ; 271)$ & ${ }^{*} \mathrm{p}<0.1 ;{ }^{* *} \mathrm{p}<0.05 ;{ }^{* * *} \mathrm{p}<0.01$
\end{tabular}




\section{A model of disaster shocks and financing contractions}

Next we present a dynamic multi-phase macro model with a focus on the causes and effects of rare large disasters. We propose a dynamic multi-phase macro model which includes a disaster phase. Though it is in the spirit of an IAM, it is rather based on a larger scale macro model which allows for tax and credit finance of climate p olicies. The model exhibits feedback effects by credit flow d ynamics a ffecting c limate variables a nd the r eal s ector as well.

As in earlier small scale models which allow for thresholds and poverty traps, such as Azariadis and Stachurski (2005) and Semmler and Ofori (2007), we permit for shifts into a model phase characterized by a persistent disaster regime. ${ }^{11}$ In earlier, simpler models increasing returns to scale, financial $m$ arket and fi nancing co nstraints, insucient insurances with high deductability, and migration of skilled labor and entrepreneurs led to economies ending up in poverty traps. Prolonged disaster phases and very slow recovery phases may be the result then.

A larger macro model with such a phase of a prolonged disaster and log-in of selfenforcing feedback effects and declining growth will be presented next. The model will be of higher dimension than the models just mentioned. This will allow us to include considerations pertaining to climate related monetary and financial p olicies. We will also model the linkages which were explored in the previous sections. The model version presented here is derived from the baseline model of appendix A.3 where details of notations and definitions can be found. This kind of a multi-phase model is technically further explored in Maurer et al. (2018) where the solution method is explained in detail.

\subsection{A three-phase Model}

Our dynamic macro model should trace the following linkages: economic production and growth leads to the extraction and usage of fossil fuel, which will give rise to $\mathrm{CO}_{2}$ emission, and increasing temperature. ${ }^{12}$ These effects will reduce economic growth and economic welfare. Mitigation and adaptation policies may be pursued by monetary and financial

\footnotetext{
${ }^{11}$ In more recent stochastic models with trapping probabilities such a regime is also referred to as a trapping region (Kovacevic and Pflug, 2 011). For m odeling e ndogenous c atastrophic $\mathrm{r}$ isk, s ee C répin and Nævdal (2019).

${ }^{12}$ We do not model the resulting temperature effects since changes in temperature, as well as in precipitation levels, are mainly due to GHG emission as discussed in section 2. Therefore we are focusing on $\mathrm{CO}_{2}$ emission as the most significant man-made GHG.
} 
instruments. Those are activated by the public sector and the monetary authority. Yet, the rise of credit and debt financed growth raises the usual question concerning sustainable debt which has to be controlled for in the long run.

In our three-phase model, allowing for disaster shocks, the above nexus is used, but split up into three phases. The first phase of our model can be considered as a stage of mitigation and adaptation policy financed through taxation. We model a second phase with small and large disasters reducing capital stock and increasing risk premia for credit financing. We focus on a model version with different types of shocks, implying disasters of different impact sizes. In the model we admit that adaptation policies can reduce vulnerability and thus reduce the occurrences of extreme events. Still, the occurrence of such an event will give rise to a multi-phase model.

In the first stage the model is the same as the single stage model in appendix A.3. The objective function is given by equation (1):

$$
W(T, X, U)=\int_{0}^{T} e^{-(\rho-n) t} \frac{\left(C\left(\alpha_{2} e_{P}\right)^{\eta}(M-\widetilde{M})^{-\epsilon}\left(\nu_{2} g\right)^{\omega}\right)^{1-\sigma}-1}{1-\sigma} d t
$$

It is subject to the following dynamics:

$$
\begin{aligned}
\dot{K} & =Y \cdot\left(\nu_{1} g\right)^{\beta}-C-e_{P}-\left(\delta d i s_{K}+n\right) K-u \psi R^{-\zeta}, \\
\dot{R} & =-u \\
\dot{M} & =\gamma u-\mu(M-\kappa \widetilde{M})-\theta\left(\nu_{3} \cdot g\right)^{\phi} \\
\dot{b} & =(\overline{r r}-n) b-\left(1-\alpha_{1}-\alpha_{2}-\alpha_{3}\right) \cdot e_{P}+\varsigma_{k} g \\
\dot{g} & =\alpha_{1} e_{P}+i_{F}-\left(\delta d i s_{g}+n\right) g+\varsigma_{k} g .
\end{aligned}
$$

Here $K$ is private (green) capital, $R$ is the stock of the non-renewable resource, $M$ is the atmospheric concentration of $\mathrm{CO}_{2}, b$ is government's debt, and $g$ is public capital. In contrast to the single phase model, a second stage - caused by a possibly large disaster shock inflicting persistent capital l osses ${ }^{13}$ - is explicitly modeled h ere. The strong disaster ${ }^{10}$ One might think of passing beyond a tipping point in climate change, as in Greiner et al. (2010), where a sequence of disasters is likely to occur. 
shock, for example, is modeled by defining $\delta d i s_{g}=\delta d i s_{K}$ jumping from 0.1 to $0.17 .{ }^{14} \mathrm{We}$ also account for a jump of the risk premium, moving from $\bar{r}=0.04$ to $\overline{r r}=0.12$. We allow for a weak shock as well and compare the effects with the strong shock. Table 4 lists the parameters for both types of shocks. Although there is some mitigation and adaptation policy in the first stage, in our BAU period, only now, in the second stage, additional credit (bond) financing will be added, $\varsigma_{k} g$, affecting the debt dynamics in equation (5) but providing also additional finance in equation (6).

In the third stage, again with the same objective function, we have no additional bond issuing any longer. Bonds are paid back by a tax rate $\tau$ on income, but the economy might face some persistent effects on their risk premia. Thus in the third phase the state equations are subject to the dynamics:

$$
\begin{aligned}
\dot{K} & =Y \cdot\left(\nu_{1} g\right)^{\beta}\left(1-\tau_{k}\right)-C-e_{P}-\left(\delta_{K}+n\right) K-u \psi R^{-\zeta}, \\
\dot{R} & =-u \\
\dot{M} & =\gamma u-\mu(M-\kappa \widetilde{M})-\theta\left(\nu_{3} \cdot g\right)^{\phi} \\
\dot{b} & =(\overline{r r r}-n) b-\left(1-\alpha_{1}-\alpha_{2}-\alpha_{3}\right) \cdot e_{P}-Y \cdot\left(\nu_{1} g\right)^{\beta} \tau_{k}, \\
\dot{g} & =\alpha_{1} e_{P}+i_{F}-\left(\delta_{g}+n\right) g .
\end{aligned}
$$

Thus, in the third stage capital losses do not occur any longer, but the previous increase in leveraging of private and public capital might still lead, in the case of the strong shock, to a considerably high risk premium of $\overline{r r r}=0.10$. We assume here that the risk premium could have been lowered by monetary policy, but would still be high due to the aftereffects of the disaster shock. By way of exemplifying our three-phase model, we pre-fix the first period from $t_{0}=0$ to $t_{1}=13$, the second period from $t_{1}=13$ to $t_{2}=23$, and last period until $T=40 .^{15}$

Table 4 contains a description of parameters defining weak and strong shocks, affecting the second phases of our model. For weak shocks the depreciation shocks for public and private capital are smaller in phase two. In addition, risk premia are also smaller in the weak shock scenario, in particular in phase two and three.

\footnotetext{
${ }^{14}$ Note that given the quality and heterogeneity of the data it is very hard to undertake more precise parameter calibration. We therefore do some robustness tests with different parameter constellations.

${ }^{15} \mathrm{~A}$ model version with time varying switching points can be found in Maurer et al. (2018).
} 
Table 4: Parameters defining weak and strong shocks for the three time periods.

\begin{tabular}{lccc}
\hline \hline Time period: & $t_{1}-t_{2}$ & $t_{2}-t_{3}$ & $t_{3}-T$ \\
\hline risk rate, weak shock & $\bar{r}=0.04$ & $\overline{r r}=0.08$. & $\overline{r r r}=0.05$ \\
risk rate, strong shock & $\bar{r}=0.04$ & $\overline{r r}=0.12$. & $\overline{r r r}=0.10$ \\
weak shock: $\sigma_{K},\left(\sigma_{G}\right)$ & $0.1,(0.075)$ & $0.12,(0.12)$ & $0.1,(0.075)$ \\
strong shock: $\sigma_{K},\left(\sigma_{G}\right)$ & $0.1,(0.075)$ & $0.17,(0.17)$ & $0.1,(0.075)$ \\
\hline \hline
\end{tabular}

\subsection{Results of the three-phase model}

The parameter shifts of table 4 are used in our subsequent simulations, whereby the effects are drawn in red lines for weak shocks and in blue lines for strong shocks. Note that overall, for all variables continuous growth is more successfully achieved without strong shocks. Overall, looking at figures 9-13, we observe that the red line is (except for the fossil fuel resource and stock of $\mathrm{CO}_{2}$ ) above the blue line.

Note that in the figures 9-13 the red line being a bove the blue line holds for consumption, private capital and public capital stock. This implies for a small shock that the economy can continuously grow with high borrowing, financing climate r elated infrastructure investments, and appropriate mitigation and adaptation policies. Thus, to overcome negative externalities, arising from $\mathrm{CO}_{2}$ emissions due to production, there is also a strong evolution of debt, since this is co-financing the mitigation and a daptation $\mathrm{p}$ olicies. With this prolonged growth process we can also observe a strong extraction of fossil fuel and a built up of a stock of $\mathrm{CO}_{2}$ emission (which is however counteracted through the climate policy measures).

Yet, with a stronger disaster shock occurring, represented by the parameters of the strong shock in table 4, which generates a significantly stronger and longer disaster period, consumption stays low, private and public capital stock stays low and so does debt. Consequently, because of lower growth and a smaller increase of capital stocks, the extraction of fossil fuel and the stock of $\mathrm{CO}_{2}$ emission is declining. This result is in line with empirical studies, see Cohen et al. (2018), who show that in times of a negative output gap emissions are declining.

Looking at details of the figures $9-13$ w e o bserve in fi gure 9 th at al though stronger disasters generate lower debt, they also generate smaller expansions of capital stocks, and much lower consumption levels. On the other hand, for weaker shocks more effective mit- 
Figure 9: Government debt in a three-phase model, red: weak shock, blue: strong shock

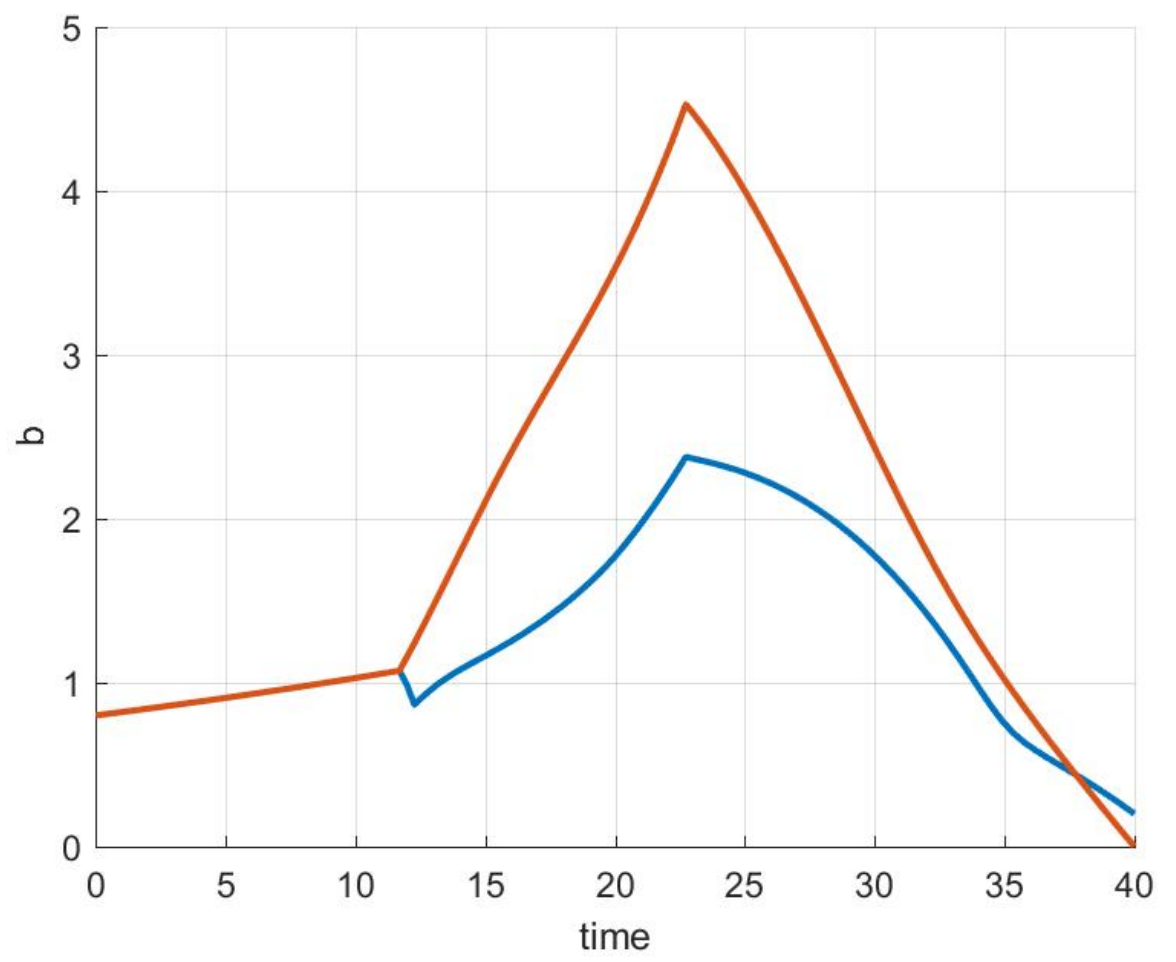

igation and adaptation policies, through the usage of financial sources, $\varsigma_{k} g$, with the aim of preventing disasters generate higher debt, but lower debt to capital ratios and higher welfare, see below. For strong shocks, as a consequence debt is rising steadily since risk premia are increasing.

Although public and private capital rise in phase one, both are suffering from the disaster shocks in phase two.

Though debt is still rising, see figure 9 , given the persistent disaster e ffects ${ }^{16}$ public and private capital is damaged and we see their size shrinking after 13 periods (see Figures 10 and 11).

As a result of strong shocks, allocation towards investment in private capital, $K$, readjusts, as the second phase - with green bond issuance - nears, see Figure 11. Yet in the period after $t_{1}$ capital stocks fall. Yet, this is not so for a weak shock where capital (and ${ }^{16}$ Note that we could define a s equence of h ighly c orrelated d isaster s hocks, a s i t i s d one i n Catalano et al. (2018), which gives roughly the same results. 
Figure 10: Government capital in a three phase model, red: weak shock, blue: strong shock

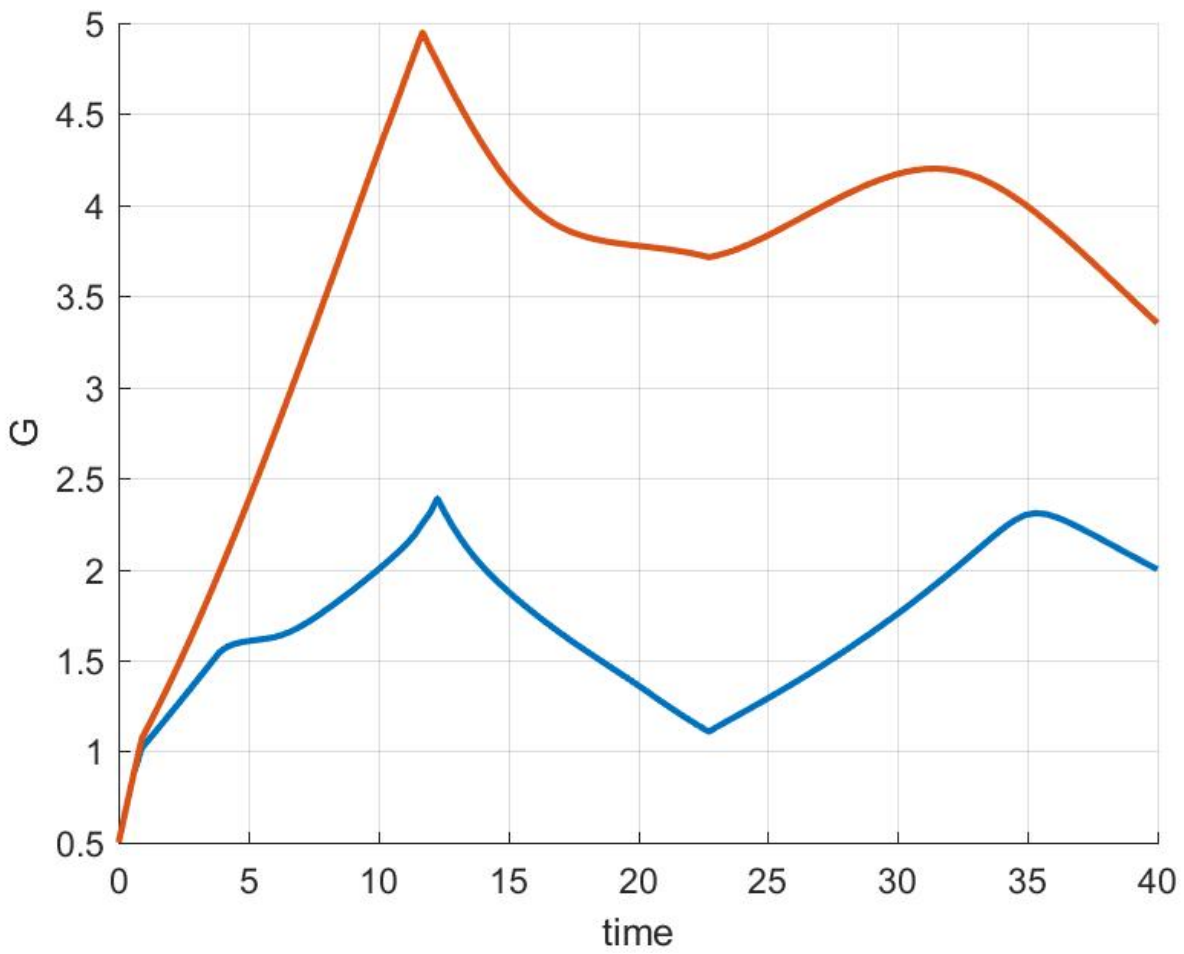

consumption) are rising.

For a strong shock, both, $g$ and $K$, decline in the second period, they remain low for a while as long as the disaster effects persist. Only in a later stage public and private capital are recovered, see Figures 10 and 11 . The rise of public and private capital in this later period is due to additional bond financing accelerating mitigation and adaption initiatives. Note that in the third phase, the repayment stage of bonds, through income taxes $\tau_{k}$, sets in. For a weak shock both private and public capital stay high.

With our initial conditions, the plots in the Figure 12a remain constant after the first phase, while the stock of emitted $M$ becomes high (figure $12 \mathrm{~b}$ ), i n p articular $\mathrm{f}$ or weak shocks, which entails a negative externality (a destructive) effect on welfare. Note also that the vulnerability of disasters is reduced with greater public capital, see equation (1).

Thus, when the level of the stock of $\mathrm{CO}_{2}$ emission, $M$, becomes high, welfare of households is reduced, see equation (1). The result of a rise of private (green) capital and public 
Figure 11: Private capital stock in a three-phase model; red: weak shock, blue: strong shock

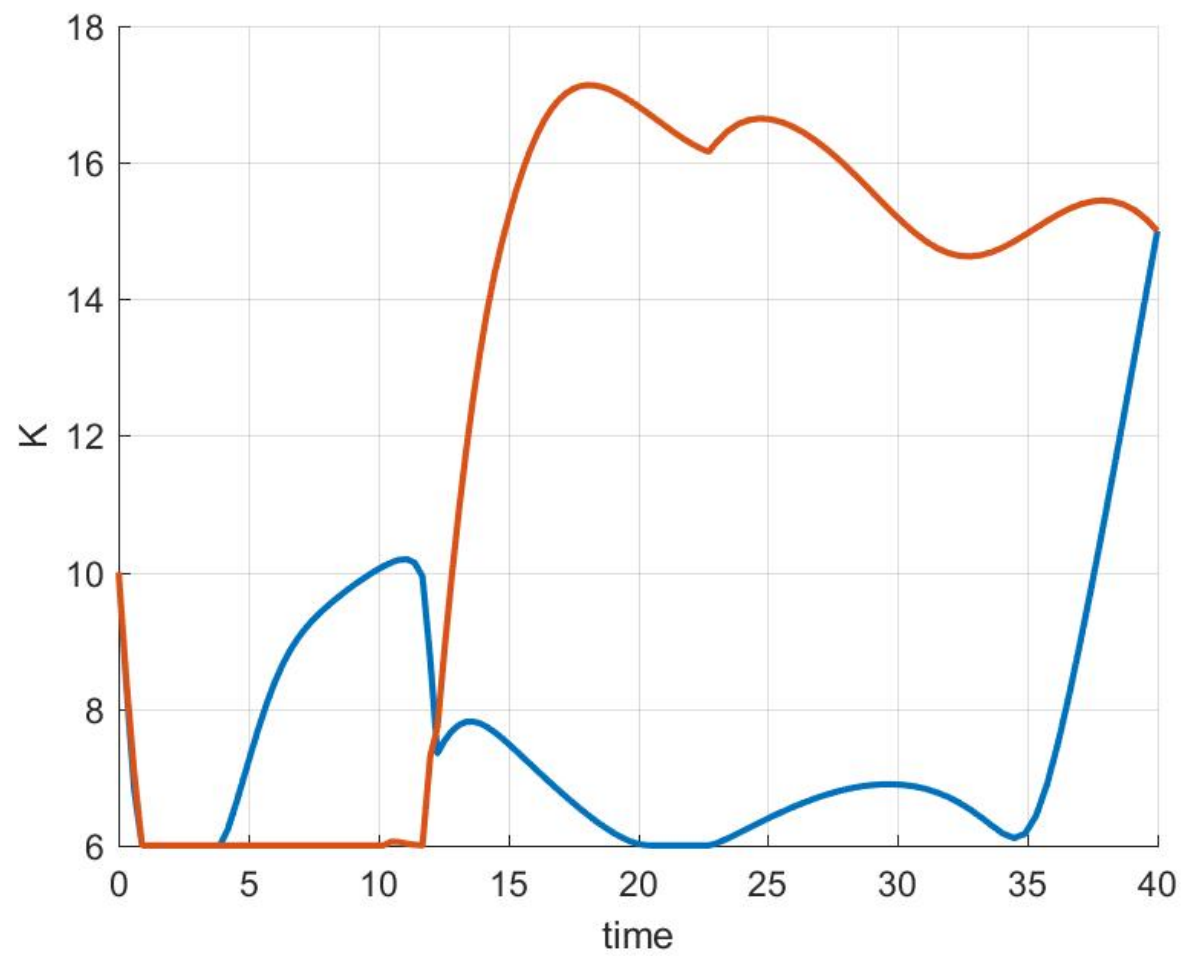

capital supporting the increase of mitigation effort and renewable energy, is preventing the stock of fossil fuel to be extracted to a greater extent. We observe this pattern until $t=T$ , in particular for weak shocks and continuous growth, with both $K$ and $g$ building up, as depicted in figures 10 and 11 , in the s econd a nd third $\mathrm{p}$ eriod. O $\mathrm{n}$ t he o ther $\mathrm{h}$ and, for a strong shock, figure $12 \mathrm{~b}$ s hows that the $\mathrm{C} \mathrm{O}_{2}$ e mission is only r ising s lightly and the stock of fossil fuel energy (the trajectory in figure $12 \mathrm{a}$ ) is o nly falling s lightly a nd $\mathrm{m}$ uch fossil energy remains unexploited.

Turning to the welfare implications of the disaster shock effects on consumption in the three-stage model, figure 13 i llustrates the $\mathrm{r}$ esults. U nlike in a m odel of a s ingle phase, see Maurer et al. (2018), where naturally consumption continuously rises without disruption (no disaster occurrence), in the current disaster driven multi-phase model there are intertemporally considerable consumption losses which will only rise slightly when $\mathrm{CO}_{2}$ emission is reduced and the stock of private (green) capital is rising again. Our computed 
Figure 12: Fossil fuel consumption in a 3-stage model, red: weak shock, blue: strong shock

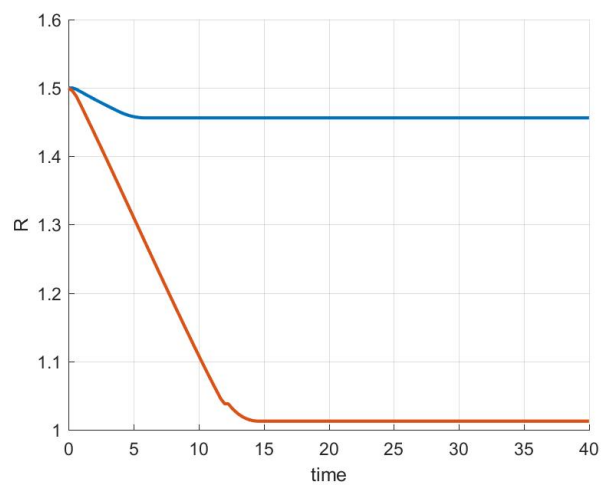

(a) Total Remaining Fossil Fuel Stock

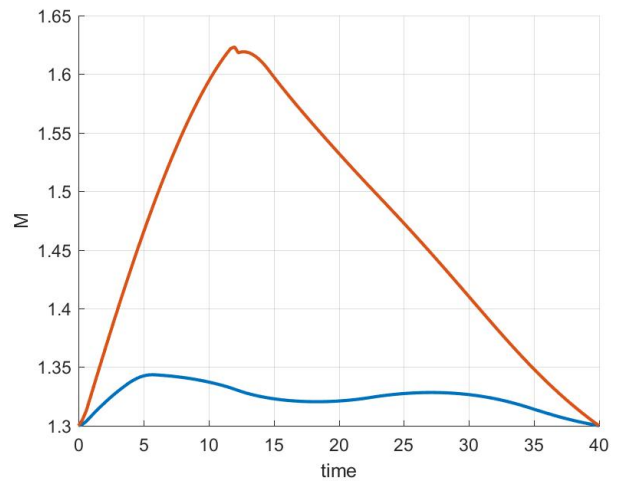

(b) Total Carbon Dioxide Emissions

value functions show that welfare in case of weak shock is $V=26.46$, and in the case of a strong shock we have $V=-36.26$.

Regarding debt sustainability we see that in terms of the debt-to-capital-stock ratio, $b / K$, the ratio is higher for strong shocks $(b / K=0.33)$ compared to weak shocks $(b / K=$ 0.25), although debt levels are increasing more strongly in the weak shock scenario, as shown above.

Note that in our proposed framework, emissions are modeled as having direct (damaging) effects on welfare, see Appendix A.3, which better encapsulates the multitude of economic, health, migration, and intrinsic environmental losses expected from insuciently abated climate change. The model also incorporates societies' adaptive responses to climate change through the use of public funds and credit flows to alleviate the disutility of emissions. In our three phase model rare disasters and long run gradual effects can be studied which are likely to have a considerable effect on productive capacity such as physical, infrastructural and human capital. In particular we have studied the effect on consumption, as shown figure 13 .

\subsection{The use of bond financing}

In general, however, even with active fiscal and financial policies, consumption may fall due to externalities from economic activities, entering as disaster risk in the welfare function. Let us specifically look at financial markets and credit flows. The amplified disaster risk 
Figure 13: Path of consumption in a three-stage model; red: weak shock, blue: strong shock

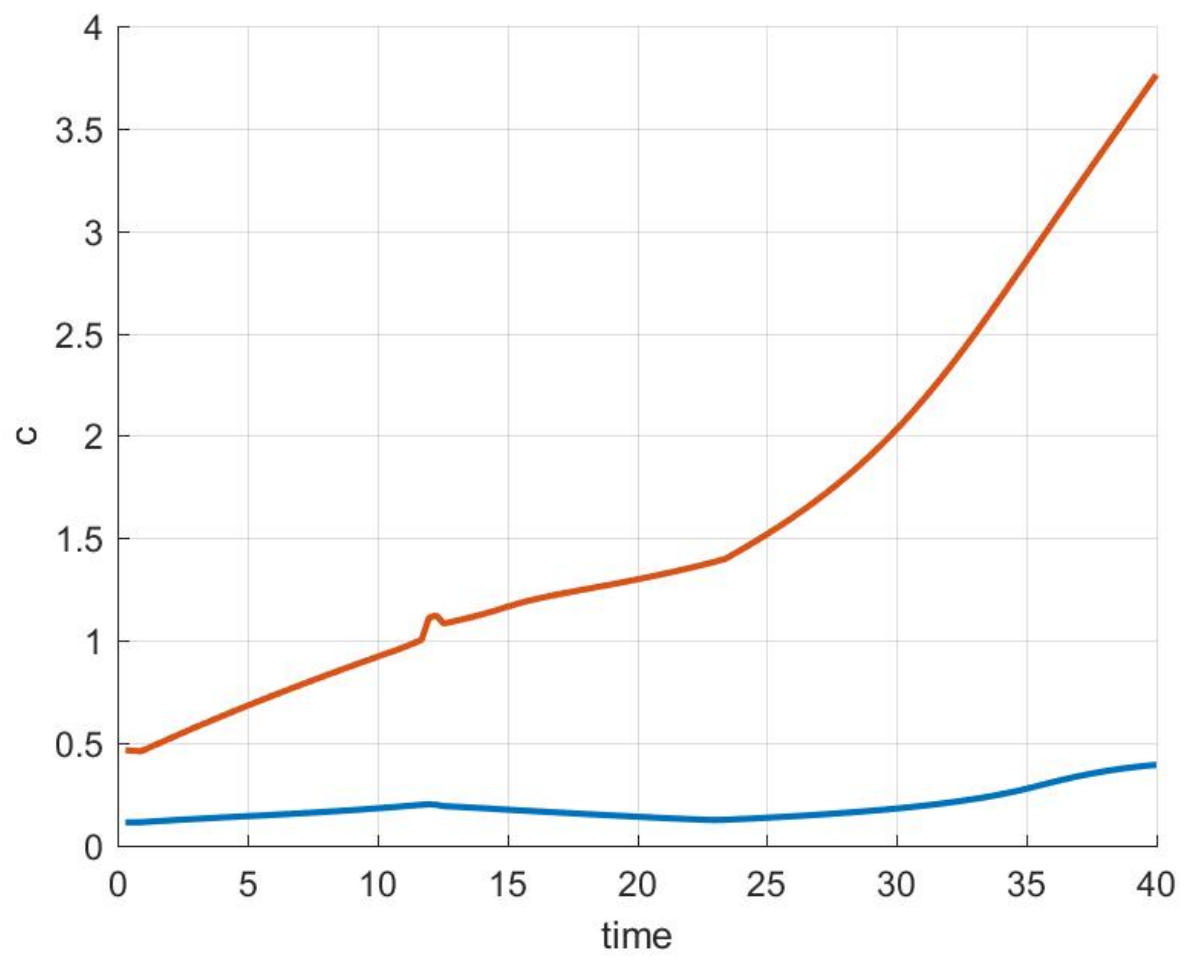

and actual disasters affect private and public capital stocks directly. In particular risk premia are affected detrimentally. On the other hand, the recovery can be accelerated by the support of climate bonds and reduced credit constraints and risk premia. Thus, due to bond issuance - bonds that have to be repaid later on by an income tax - output, private and public capital and consumption, can rise again after the disaster stage. As discussed bond issuing has significant b enefits si nce it he lps sc aling up mi tigation, ad aptation, and recovery policies.

We build heavily on the financing tools s uch a s (long) m aturity b onds h ere. Though details on such financing mechanism are discussed in Flaherty et al. (2017) and Gevorkyan et al. (2016), we want to highlight a few specifics a nd p ractical d imensions $r$ elevant in our three-phase modeling context. We have argued that credit (bond) financing allows for better control and scaling of climate policies. Thus financing $m$ itigation a nd adaptation policies as well as financing recoveries after disasters is improved by bond financing. 
With respect to mitigation policies, bond financing c an s timulate the d ecelerating of greenhouse gas emissions in a timely manner, allows for energy eciency, changes in energy mix in industrial production, services, transportation, and food production, and permits the development of new renewable energy sources, energy transportation grids, and infrastructure networks.

Regarding adaptation it can provide funds which can help in reducing frequency and severity of disasters, assist in the reduction of extreme events which arise from increased local frequency - and possibly severity - of storms, coastal flooding, d roughts, extreme temperature events, and helps reversing slow long-run impacts from extreme weather events, global water cycles, deterioration of air quality, oceanic warming, shrinking of sea ice cover, deterioration of snow cover and glaciers, and sea level rise. It could also be used for building up early warning systems - which has been done with respect to financial crises - but which could also act to reduce vulnerability in the case of climate disasters (Thomas et al., 2013).

Bond financing can also be used for climate related infrastructure concerning the above suggested green mitigation and adaptation policies as well as for sustainable water management, sustainable land use, biodiversity conservation, grids for renewable energy, clean transportation, and protection of coastal and other areas from flooding a nd destruction, thus also reducing vulnerability.

Bond financing is likely to be less ecient for recovery policies, but it is expected to be very effective in rebuilding public infrastructure. Other monetary and credit policies are likely to be more suitable as recovery policies. This will be discussed below.

Concerning types of bonds there are government-backed bonds and a variety of municipal government bonds, for example for investments in renewable energy projects, and green bonds issued by the business sector. Often these are asset-backed securities which are similar to traditional bonds by generating some future revenue stream. Covered bonds are a type of asset-backed security that are guaranteed by the issuing agency. Bonds could also be bundled, as soft and hard bonds, and low and high risk bonds, that might be packaged and sold as investment vehicle- though given some recent experiences the latter might be limited.

Various types of agencies have been actively providing bond financing. Agencies issuing green bonds fall into three general categories: private businesses, governments and municipalities, and multilateral agencies. The particular bond characteristics tend to vary by type of issuer. Numerous municipalities in developed and developing countries have turned to green bonds as a means of raising green funds. Some investment banks and other financial 
institutions have also taken note, and have introduced green bonds as part of their offerings. There are also multilateral agencies issuing green bonds for example the World Bank, which substantially helped funding climate policies through issuing bonds for developing countries. ${ }^{17}$ The number of green bonds issued, as well as the proportion of global GHG emissions which are covered by carbon tax policy, has thereby increased dramatically in recent years. Figure 14 shows this development since $1990 .{ }^{18}$ The figure shows that both series have been growing strongly in recent years: starting between 2011 and 2013 we witness a clear upward trend for both series as more and more countries are introducing carbon tax policies to tackle climate change.

Lastly, one might ask whether the current macro and monetary policy environment might be conducive to phase in such green bonds? In particular long maturity bonds, because of low interest rates, low risk premia and low expected inflation rates should make long-term bonds a good sell. Furthermore, bonds are now largely inflation adjusted, such as US TIPS to protect long term bonds. It is expected that the current and future interest rates will stay low for quite a while and this, together with low term premia, and low expected inflation rates, is likely to keep the expected future term structure flat.

Concerning the buyers' side - households' preferences for those bonds - it looks certain that green bonds will be considered safe long term assets for households, whereas assets from fossil fuel appear to be stranded assets, possibly triggering financial meltdowns, see Battiston et al. (2017). On the other hand, world-wide, funds of $\$ 80$ to $\$ 100$ trillion or more are available as part of large scale portfolios of wealth funds, university endowments, insurances and pension funds and they could include climate bonds as part of their portfolio.

\footnotetext{
${ }^{17}$ An additional idea is to issue diaspora bonds, see Gevorkyan (2008).

${ }^{18}$ We want to thank Arkady Gevorkyan for providing us with the data for figure 14 .
} 
Figure 14: Carbon Tax Policy and Issuance of Climate Bounds. The left hand scale measures the proportion of global GHG emissions covered by carbon tax policy. The green bars represent their values over time. The right hand scale measures the amount of climate bonds issued in USD (in millions). The blue line represents their value over time. Amount of climate bonds issued is reported only up until $03 / 20 / 2019$. The number of issued bonds for 2019 is interpolated for the remaining 9 months. No data is available for the years 1993-1995, 1997-1999, 2001-2003 and 2005-2006. Source: Climate Bond Initiative, World Bank.

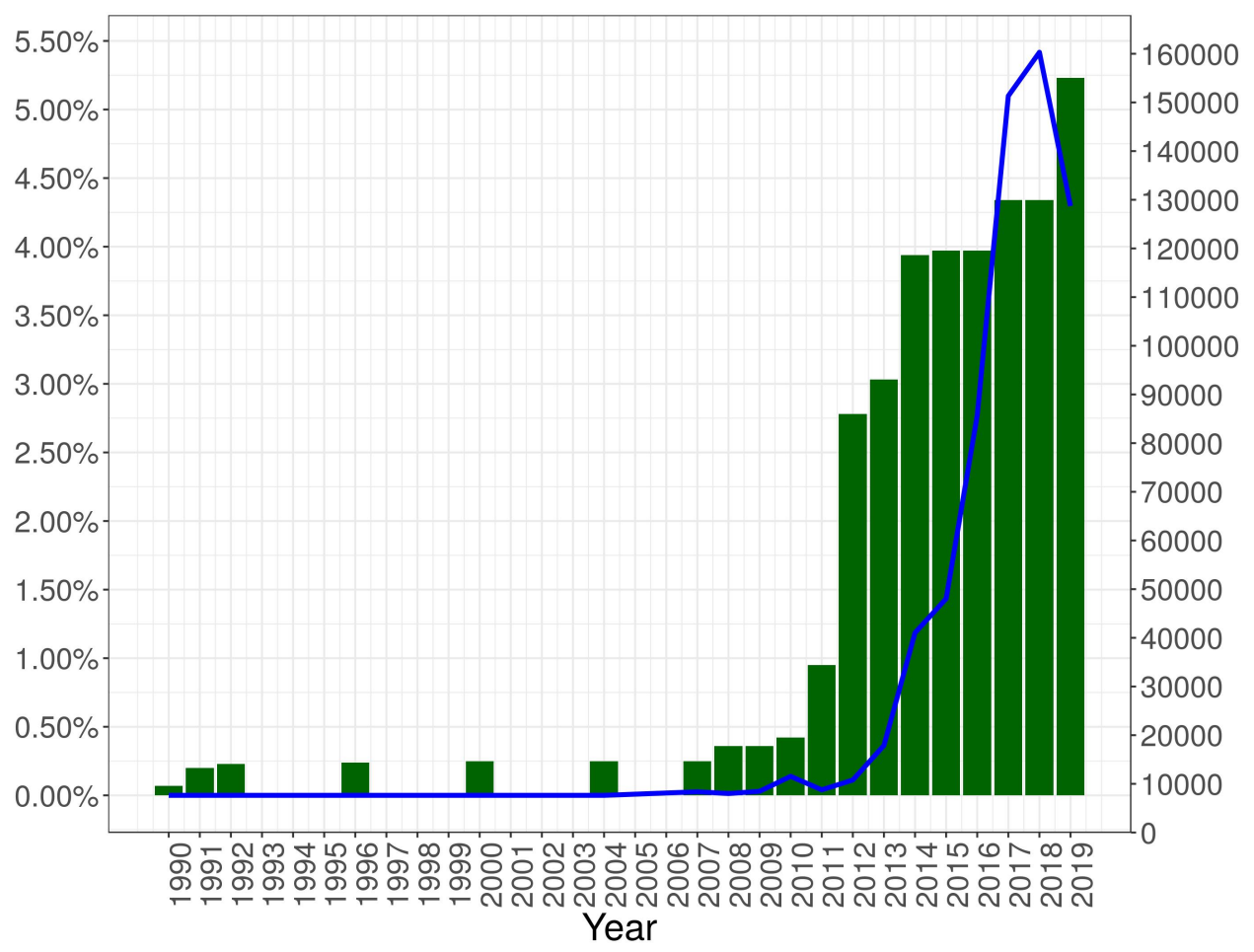




\section{Other policies for the green transition and disaster man- agement}

Mitigation and adaptation policies and disaster risk prevention and recoveries may also be supported more directly by monetary policy. Important aspects of the use of monetary policy in support of climate policy are discussed in Fratzscher et al. (2017), McKibbin et al. (2017), and Monnin (2018). The latter also includes discussions on the role of the financial sector at large, including banks and central banks. ${ }^{19}$

Monetary polices could also be more supportive with respect to climate bonds. For example, if central banks accept green bonds as collateral, they could stimulate climate finance. There is some virtuous cycle: Central banks prefer rated bonds as collateral and rating firms try to rate climate bonds and they rate those bonds higher if they are accepted by central banks as collateral. On the other hand there exists a carbon foot print index of equity which may not only help issuing green bonds, but aid in preventing a fire sale of fossil fuel assets. Central banks could also ease credit flows after disasters,${ }^{20}$ in particular to overcome bottlenecks in the supply of goods and services, in infrastructure, transport and other private and public sectors.

In terms of fiscal and financial policies there is a policy trade-off between the use of funds allocated to climate related infrastructure, for mitigation of GHG emissions and against extreme events to ameliorate local damages from such events. Harmful events might occur in spite of mitigation, but the probability of an extreme and harmful event is reduced with greater mitigation efforts. The optimal mix and the state and time dependencies of those policies are studied in our model variant, but it is also shown that the constraints are relaxed through borrowing and bond issuing. Our model also suggests that besides issuing bonds, grants from donors and development aid, tax and government expenditure can be used for climate related infrastructure and for mitigation and adaptation policies.

However, since the major burden of future disasters will probably be located in devel-

\footnotetext{
${ }^{19}$ We want to note that after the 2007-9 meltdown a lot of literature has been generated on the prevention and mitigation of financial disasters through financial market regulation, such as regulation on requirements for needed capital buffers for banks, system risk supervision, restriction of proprietary trading, policies on to big to fail, etc. Monetary and financial $\mathrm{p}$ olicies $\mathrm{h}$ ave $\mathrm{b}$ een $\mathrm{d}$ eveloped $\mathrm{t} \mathrm{o} \mathrm{p}$ revent a nd $\mathrm{t} \mathrm{o}$ adapt when vulnerabilities and financial d isasters $\mathrm{r}$ isks o ccur. M onetary $\mathrm{p}$ olicy $\mathrm{h}$ as $\mathrm{m}$ oved f rom conventional to unconventional monetary policy with large asset purchasing programs, in particular bond purchasing programs, see Faulwasser et al. (2018), and also Gross et al. (2019).

${ }^{20}$ There is literature that views credit flows a s a major d river for expansions a nd c ontractions. For a survey, see Faulwasser et al. (2018).
} 
oping and low income countries, there will be significant financing bottlenecks. Although we have introduced a large set of policy measures which can be calibrated to country- and institution-specific circumstances, those are not all applicable to low and middle income countries. For details on limitations of bond issuing and credit expansions in low income countries, see UNCTAD (2018) and Banga (2018). Thus, one also needs to consider other types of policies so that those countries or regions do not fall into a poverty trap. This is in particular relevant for small low income countries with restricted opportunities in achieving scale effects from credit expansion and bond issuing.

Indeed, much recent research places emphasis on the changing level of risk and vulnerabilities faced by developing countries as they allocate investment toward growth strategies, adapting to climate change and emissions mitigation. Recent research on climate disaster risk by Burke et al. (2015) and IMF (2017) demonstrate that low and middle income countries are affected the most. This research also shows that in particular low income countries will be more vulnerable to climate related disasters, as well as suffering from gradually deteriorating productivity. In addition, they also lack the economic and financial capacity to adapt. Some estimates suggest that indirect losses might be even greater than direct losses for low income countries.

There is more specific work to be done with respect to financing in low income countries. Adam and Bevan (2014) and Bevan and Adam (2016) suggest, given the credit constraints in low income countries and high risk premia for insurances, that there are not only direct disaster impacts but also indirect long run effects and those countries lack the finance for rapid adaptation and reconstruction. The studies examine sovereign disaster risk insurance, increased taxation, and budget reallocation as alternative financing mechanisms. This is especially important for countries where increased borrowing, either through the bond market or banks, is impractical as pointed out by Banga (2018) and Marto et al. (2017).

Others, such as Catalano et al. (2018), stress the importance of preventive actions and of policy buffers, designed to enhance resilience to shocks. Furthermore the ease of borrowing constraints, greater reserves, and reserve fund accumulation is suggested. Low income countries and regions have limited access to issuing climate bonds and exercise little borrowing power. Besides tax increases Catalano et al. (2018) suggest risk pooling through self-insurance or some collective insurance schemes, grants from donors, and build up of financial buffers and disaster funds for contingencies. Yet, as they stress, the issue of debt sustainability, as we have discussed above, needs to be addressed as well.

Indeed a broader concept of risk pooling could also aim at mechanisms of private or 
public insurance schemes, multilateral safety nets, regional catastrophic insurance schemes, and so on. Others have suggested that, beside donor grants, fiscal and financial policies and risk pooling and insurance funds, monetary policy should step in to provide for disaster affected regions and countries with low interest rate loans and sufficient credit flows to allow for reconstruction and recovery to avoid hysteresis effects on productive capacity. ${ }^{21}$

\section{Conclusions}

In this paper we relate the extensive research on financial crises disasters, and their triggered macro feedback effects, to climate disaster risk, using modeling insight of the former studying the latter. In the former literature the impact of rare large disasters on the financial sector, output and consumption losses is studied. A particular focus lies on the destruction of capital stocks and a jump in risk premia after rare large economic and financial crises events. Much recent research in the economics of climate change has also explored the link between GDP growth, greenhouse gas emission, global temperature rise, and climate-related disasters. Yet, to the best of our knowledge, the macroeconomic effects, such as a decline of output, loss of capital value and sudden jumps in risk premia and borrowing constraints have not been addressed in detail.

Our dynamic macroeconomic framework links economic growth to GHG emissions, the use of a $\mathrm{CO}_{2}$-emitting non-renewable resource such as fossil fuels, temperature rise and the vulnerability to climate disasters. Following up the issue whether climate disaster risks have increased, in terms of frequency and severity is not an easy task. A conclusive answer whether we can observe an increase in the likelihood of extreme outcomes and an increase in the probability of potentially irreversible and catastrophic damages - as suggested by Weitzman (2009) - could not be convincingly provided given the quality and quantity of the data. We might see stronger links for some types of disasters, but not for others and we might observe these patterns only for certain groups of countries and regions.

Moreover, quantifying the link between the likelihood of extreme outcomes and catastrophic damages depends on the definition of vulnerability. Higher vulnerability might be given by the link between GHG emission and temperature rise - increasing the vulnerability to disasters. But vulnerability is also defined by how much adaptation has taken place, and how effective it has been. Vulnerability, however, is also affected by early warning systems,

\footnotetext{
${ }^{21}$ Which means to avoid trapping probabilities as discussed in Kovacevic and Pflug (2011).
} 
precautionary measures and disaster preventing infrastructure. Thus, an increased frequency can be accompanied by lower severity resulting from reduced vulnerability. Thus, successful adaptation policy may reduce the severity of more frequent disasters. Such a feedback nexus is incorporated in our macro model, but could not be tested directly.

We thus used a dynamic multi-phase macro model with mitigation and adaptation policy built in - which are likely to counteract the vulnerability of disaster risk arising from GHG emission and temperature rise. Beside financial instruments such a credit and climate bonds, other policies such as monetary policy were considered, particularly the effect of the latter on credit constraints and risk premia. We have shown that mitigation and adaptation policies as well as disaster risk prevention and recovery can be significantly supported by many tools, including insurance and monetary policies. A sufficient implementation of those measures might help supporting a green transition but may also aid in preventing sudden climate-related financial market instabilities. 


\section{References}

Adam, C. S. and Bevan, D. (2014). Public Investment, Public Finance, and Growth; The Impact of Distortionary Taxation, Recurrent Costs, and Incomplete Appropriability. IMF Working Papers 14/73, International Monetary Fund.

Arellano, M. (1987). Combuting robust standard errors for within-groups estimators. Oxford Bulletin of Economics and Statistics, 49:431-434.

Azariadis, C. and Stachurski, J. (2005). Poverty traps. In Aghion, P. and Durlauf, S., editors, Handbook of Economic Growth, volume 1, Part A, chapter 05. Elsevier, 1 edition.

Banga, J. (2018). The green bond market: a potential source of climate finance for developing countries. Journal of Sustainable Finance ${ }^{3}$ Investment, pages 1-16.

Barro, R. J. (2006). Rare disasters and asset markets in the twentieth century. The Quarterly Journal of Economics, 121(3):823-866.

Barro, R. J. and Ursua, J. F. (2008). Macroeconomic crises since 1870. Working Paper 13940, National Bureau of Economic Research.

Battiston, S., Monasterolo Mandel, A., Schuetze, F., and Visentin, G. (2017). A climate stress-test of the financial system. Nature Climate Change, 7.

Bernard, L. and Semmler, W. (2015). The Oxford Handbook of the Macroeconomics of Global Warming. OUP Catalogue. Oxford University Press.

Bevan, D. and Adam, C. (2016). Financing the reconstruction of public capital after a natural disaster. Policy Research Working Paper 7718, World Bank, Washington, DC.

Bonen, A., Loungani, P., Semmler, W., and Koch, S. (2016). Investing to mitigate and adapt to climate change : A framework model. Working Paper 16/164, International Monetary Fund.

Bouwer, L. M. (2011). Have disaster losses increased due to anthropogenic climate change? Bulletin of the American Meteorological Society, 92(1):39-46.

Burke, M., Hsiang, S., and Miguel, E. (2015). Global non-linear effect of temperature on economic production. Nature, 527:235-239.

Cantelmo, A., Melina, G., and Papageorgiou, C. (2017). Climate change and macroeconomic outcomes in low-income countries. Technical report, IMF.

Catalano, M., Forni, L., and Pezzolla, E. (2018). Climate-change adaptation: The role of fiscal policy. Technical report, University of Bologna. 
Cohen, G., Jalles, J. T., Loungani, P., and Marto, R. (2018). The long-run decoupling of emissions and output: Evidence from the largest emitters. Energy Policy, 118:58 - 68.

Coronese, M., Lamperti, F., Chiaromonte, F., and Roventini, A. (2018). Natural disaster risk and the distributional dynamics of damages . LEM Working Paper Series 2018/22, Laboratory of Economics and Management (LEM), Sant'Anna School of Advanced Studies, Pisa, Italy.

Crépin, A.-S. and Nævdal, E. (2019). Inertia risk: Improving economic models of catastrophes. The Scandinavian Journal of Economics, forthcoming.

Faulwasser, T., Gross, M., and Semmler, W. (2018). Credit cycles and monetary policy in a model with regime switches. Technical report.

Fernandez-Villaverde, J. and Levintal, O. (2016). Solution methods for models with rare disasters. Working Paper 21997, National Bureau of Economic Research.

Flaherty, M., Gevorkyan, A., Radpour, S., and Semmler, W. (2017). Financing climate policies through climate bonds - a three stage model and empirics. Research in International Business and Finance, 42:468 - 479 .

Fratzscher, M., Grosse Steffen, C., and Rieth, M. (2017). Inflation Targeting as a Shock Absorber. Working papers 655, Banque de France.

Gabaix, X. (2011). Disasterization: A simple way to fix the asset pricing properties of macroeconomic models. The American Economic Review, 101(3):406-409.

Gevorkyan, A. (2008). Fiscal policy and alternative sources of public capital in transition economies: the diaspora bond. Journal of International Business and Economy, 9(2):3361.

Gevorkyan, A., Flaherty, M., Heine, D., Mazzucato, M., Radpour, S., and Semmler, W. (2016). Financing climate policies through carbon taxation and climate bonds - theory and empirics. Technical report, The New School for Social Research.

Gourio, F. (2012). Disaster risk and business cycles. American Economic Review, 102(6):2734-66.

Greiner, A., Gruene, L., and Semmler, W. (2010). Growth and climate change: Threshold and multiple equilibria. In Crespo Cuaresma, J., Palokangas, T., and Tarasyev, A., editors, Dynamic Systems, Economic Growth, and the Environment, volume 12 of Dynamic Modeling and Econometrics in Economics and Finance, pages 63-78. Springer, Berlin, Heidelberg.

Gross, M., Loungani, P., and Semmler, W. (2019). Unconventional monetary policy in a nonlinear quadratic model. Technical report. 
Guha-Sapir, D., D'Aoust, O., Vos, F., and Hoyois, P. (2013). The Economic Impacts of Natural Disasters. Oxford University Press.

Gumbel, E. (1935). Les valeurs extremes des distributions statistiques. Annales de l'institut Henri Poincare, 5(2):115-158.

Gumbel, E. (1958). Statistics of Extremes. Columbia University Press.

Hochrainer, S., Mechler, R., and Pflug, G. (2009). Assessing current and future impacts of climate-related extreme events. the case of bangladesh. Interim Report IR-09-030, International Institute for Applied Systems Analysis.

Hochrainer-Stigler, S., Mechler, R., Pflug, G., and Williges, K. (2014). Funding public adaptation to climate-related disasters. estimates for a global fund. Global Environmental Change, 25:87-96.

Hotelling, H. (1931). The economics of exhaustible resources. Journal of Political Economy, $39(2): 137-175$.

IMF (2017). World Economic Outlook, October 2017: Seeking Sustainable Growth: ShortTerm Recovery, Long-Term Challenges. World Economic Outlook. International Monetary Fund.

Ingham, A., Ma, J., and Ulph, A. (2007). Climate change, mitigation and adaptation with uncertainty and learning. Energy Policy, 35(11):5354 - 5369.

IPCC (2012). Managing the risks of extreme events and disasters to advance climate change adaptation. a special report of the intergovernmental panel on climate change. Technical report, Intergovernmental Panel on Climate Change, Cambridge.

IPCC (2013). Summary for policymakers. In The Physical Science Basis. Contribution of Working Group 1 to the Fifth Assessment Report of the Intergovernmental Panel of Climate Change. Fifth Assessment Report. Cambridge University Press, Cambridge.

Kovacevic, R. M. and Pflug, G. C. (2011). Does insurance help to escape the poverty trap? - a ruin theoretic approach. Journal of Risk and Insurance, 78(4):1003-1028.

Lean, J. L. and Rind, D. H. (2008). How natural and anthropogenic influences alter global and regional surface temperatures: 1889 to 2006. Geophysical Research Letters, 35(18).

Marto, R., Papageorgiou, C., and Klyuev, V. (2017). Building resilience to natural disasters: An application to small developing states. IMF Working Paper 17/223, International Monetary Fund.

Maurer, H. and Semmler, W. (2011). A model of oil discovery and extraction. Applied Mathematics and Computation, 217(13):1163-1169. 
Maurer, H., Semmler, W., and Bonen, T. (2018). Financing climate change policies: A multi-phase integrated assessment model for mitigation and adaptation. Technical report, The New School.

McKibbin, W., Morris, A., Panton, A., and Wilcoxen, P. (2017). Climate change and monetary policy: Dealing with disruption. CAMA Working Paper 77/2017, Centre for Applied Macroeconomic Analysis.

Miller, R. L., Schmidt, G. A., Nazarenko, L. S., Tausnev, N., Bauer, S. E., DelGenio, A. D., Kelley, M., Lo, K. K., Ruedy, R., Shindell, D. T., Aleinov, I., Bauer, M., Bleck, R., Canuto, V., Chen, Y., Cheng, Y., Clune, T. L., Faluvegi, G., Hansen, J. E., Healy, R. J., Kiang, N. Y., Koch, D., Lacis, A. A., LeGrande, A. N., Lerner, J., Menon, S., Oinas, V., Pérez García-Pando, C., Perlwitz, J. P., Puma, M. J., Rind, D., Romanou, A., Russell, G. L., Sato, M., Sun, S., Tsigaridis, K., Unger, N., Voulgarakis, A., Yao, M.S., and Zhang, J. (2014). Cmip5 historical simulations (1850-2012) with giss modele2. Journal of Advances in Modeling Earth Systems, 6(2):441-478.

Mohleji, S. and Pielke, R. (2014). Reconciliation of trends in global and regional economic losses from weather events: 1980-2008. Natural Hazards Review, 15(4):04014009.

Monnin, P. (2018). Central banks and the transition to a low-carbon economy. Working Paper 2018/1, Council on Economic Policies.

Pindyck, R. (1978). The optimal exploration and production of nonrenewable resources. Journal of Political Economy, 86(5):841-61.

Rietz, T. A. (1988). The equity risk premium a solution. Journal of Monetary Economics, $22(1): 117-131$.

Semmler, W., Maurer, H., and Bonen, A. (2018). Control Systems and Mathematical Methods in Economics. Lecture Notes in Economics and Mathematical Systems, volume 687, chapter An Extended Integrated Assessment Model for Mitigation and Adaptation Policies on Climate Change, pages 297-317. Springer.

Semmler, W. and Ofori, M. (2007). On poverty traps, thresholds and take-offs. Structural Change and Economic Dynamics, 18(1):1-26.

Thomas, V., Albert, J., and Perez, R. (2013). Climate-related disasters in asia and the pacific. ADB Economic Working Paper 358, Asian Development Bank, Manila.

Thomas, V. and Lopez, R. (2015). Global increase in climate-related disasters. Working Paper 466, Asian Development Bank.

UNCTAD (2018). The Least Developed Countries Report 2017. United Nations Conference on Trade and Development. 
Weitzman, M. L. (2009). Additive damages, fat-tailed climate dynamics, and uncertain discounting. Economics, 2009-39. 


\section{A Appendix}

\section{A.1 Fixed effects Coefficients for Panel Model}

The following table contains the fixed effects coefficients for our panel model in Table 2 .

Table 5: Fixed Effects for Table 2. Dependent variable represents the number of disaster events for a given year (Disaster Frequency). Independent variables include the lagged value of dependent variable (Disaster Frequency $t_{-1}$ ) and the sum of the current and 17 most recent increases in $\mathrm{CO}_{2}$ concentration in the atmosphere, expressed as a mole fraction in dry air (ppm) (Sum of $\mathrm{CO}_{2}$ increases). Standard errors are given in parenthesis. Model Complete Data-set considers all disasters in the EMDAT database. Model Large Disasters Data-set only includes disasters with at least 1,000 affected or 100 people killed.

\begin{tabular}{lcc}
\hline \hline & \multicolumn{2}{c}{ Dependent variable: } \\
\cline { 2 - 3 } & \multicolumn{2}{c}{ Disaster Frequency } \\
& Complete Data-set & Large Disasters Data-set \\
\hline EAS & 7.6949 & 4.7931 \\
& $(4.5543)$ & $(3.3237)$ \\
ECS & -6.9858 & -11.4663 \\
& $(4.6638)$ & $(3.8024)$ \\
LCN & -5.8552 & -5.1752 \\
& $(4.6501)$ & $(3.4959)$ \\
MEA & -22.6248 & -15.7693 \\
& $(5.2799)$ & $(4.0410)$ \\
NAC & -15.9695 & -10.4356 \\
& $(4.9672)$ & $(3.7610)$ \\
SAS & -12.6648 & -7.8858 \\
& $(4.8411)$ & $(3.5922)$ \\
SSF & -10.4200 & -6.8432 \\
& $(4.7600)$ & $(3.5461)$ \\
\hline
\end{tabular}

\section{A.2 Empirics of climate disaster cost}

Figure 15 depicts results on the logarithm of real - deflated by the GDP deflator - estimated damages between 1976 and 2017. Due to a lack of data we are not showing results by regions here, but worldwide aggregated data only. As can be seen from the figure, $d$ ata o $n$ real damages is hard to analyze because of many missing values. Indeed, for some disaster categories real damages are missing for certain years. 
Figure 15: Logarithm of estimated real damages for climate related disaster between 1976 and 2017 by disaster category.

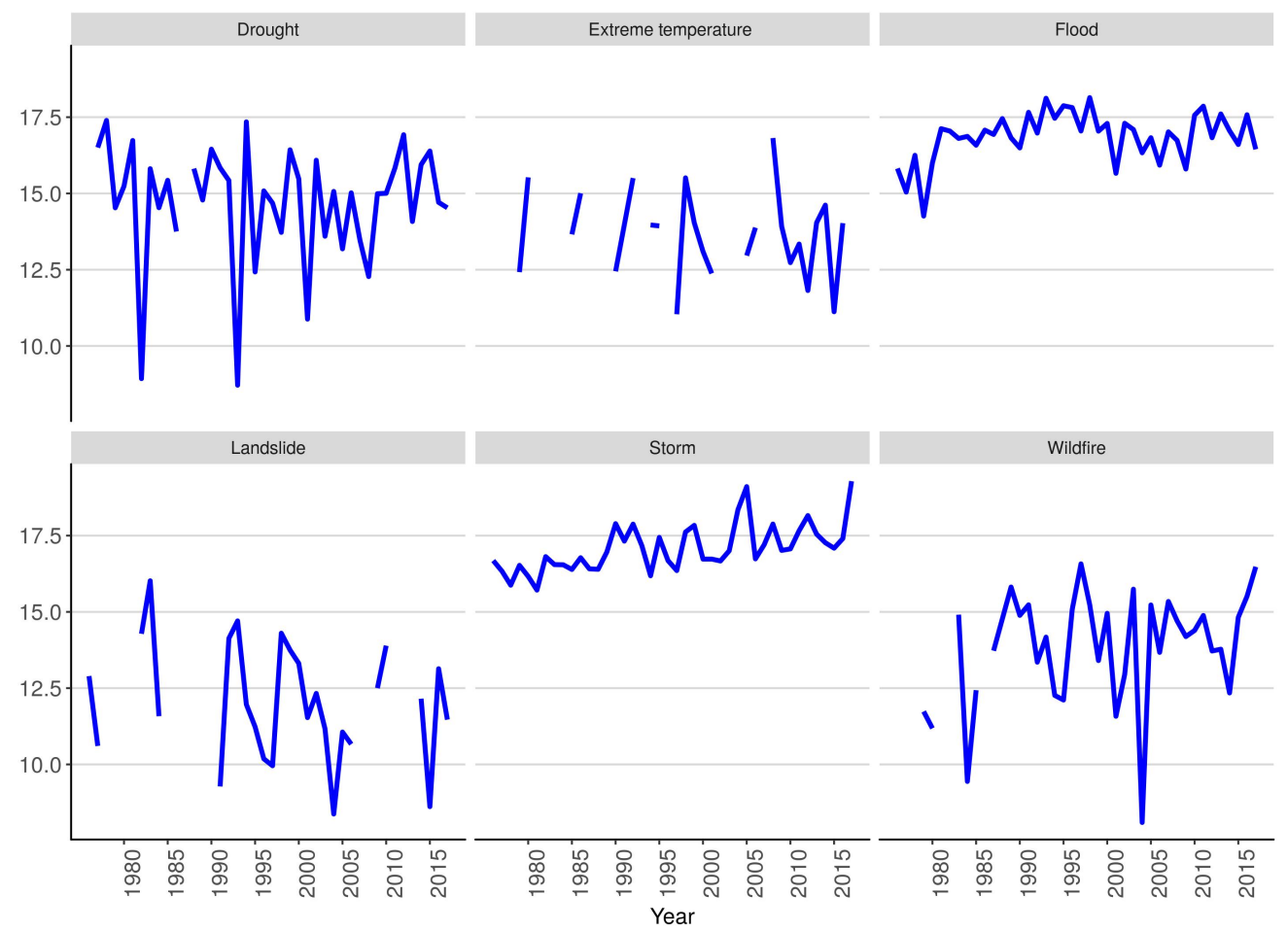

Data shown in Figure 15 is summed up and plotted in Figure 16 as total estimated damage. Figure 15 shows that real damage costs increased for the disaster category storm in recent years. Fluctuations in storm related damages also dominate aggregated damage costs (Figure 16). Thus, given the severe data issues at hand, we focus on the number of disasters per year instead of disaster cost in our empirical analysis. Furthermore, societal changes, such as population and wealth increases, and exceptionally big disasters, e.g. Hurricane Sandy, may distort damage costs. In fact, Mohleji and Pielke (2014) argue that societal changes are sucient to explain increasing disaster damages (see also Bouwer, 2011).

\section{A.3 Base line macro dynamic model}

As suggested above, our dynamic decision model should trace the following linkages: economic growth leads to the extraction and use of fossil fuel, which will give rise to $\mathrm{CO}_{2}$ emission, increasing temperature and reducing economic growth and economic welfare. Mitigation and adaptation policies may be pursued more or less successfully by fiscal and/or 
Figure 16: Logarithm of estimated real damages for climate disaster between 1976 and 2017; total.

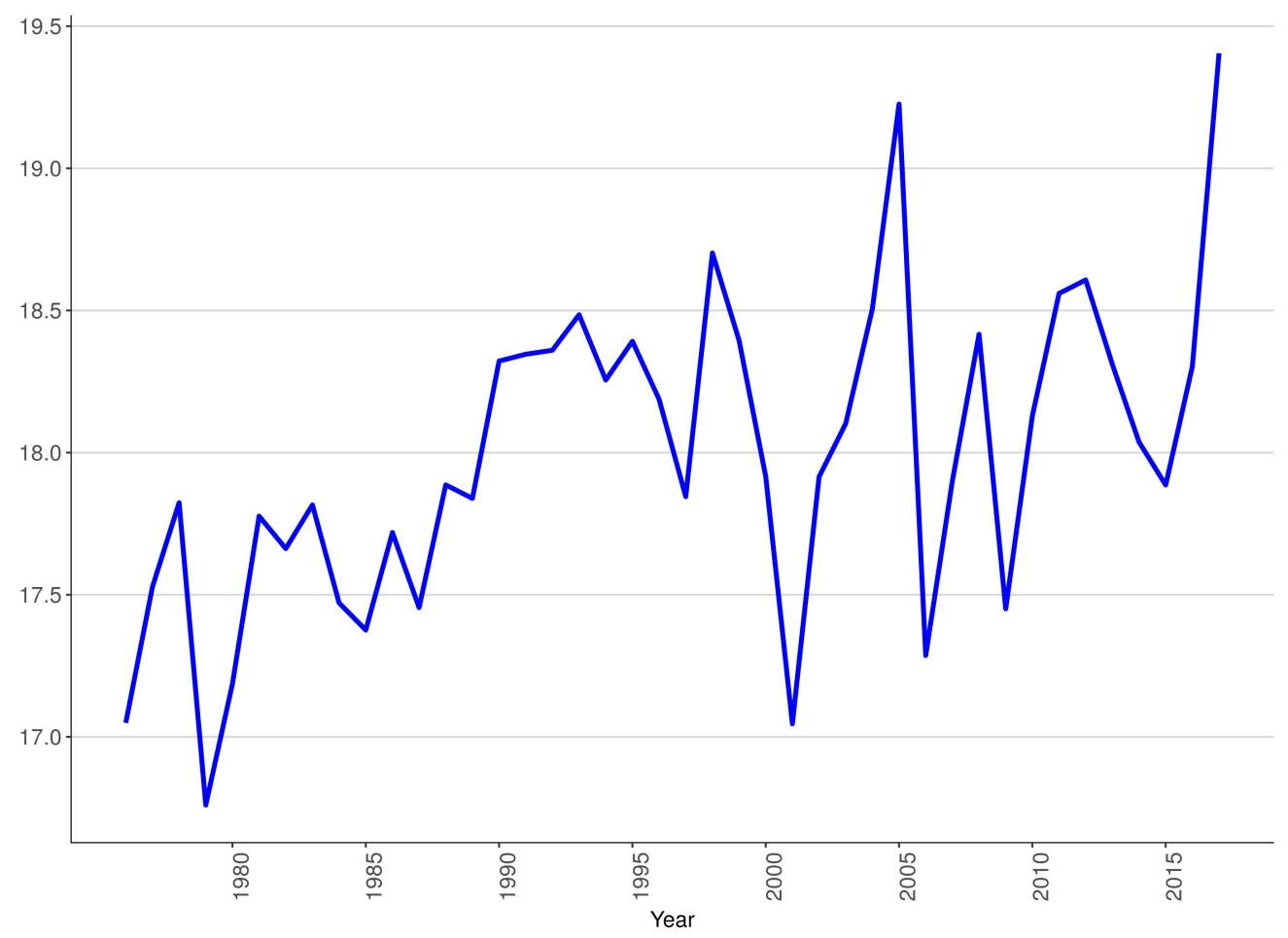

financial instruments. Those are activated by the public sector and public capital. But the rise of debt financed public capital raises the problem of sustainable debt which has to be controlled for.

These features are embodied in the following baseline one-phase model that extends the common IAM but can be turned into a multi-stage model, see section 3. Our extended integrated assessment model has 5 state variables.

$$
X=(K, R, M, b, g) \in \mathbb{R}^{5},
$$

where $K$ is private (green) capital, $R$ is the stock of the non-renewable resource, $M$ is the atmospheric concentration of $\mathrm{CO}_{2}, b$ is the government's debt, and $g$ is public capital. The dynamic system of the IAM is defined according to

$$
\begin{aligned}
\dot{K} & =Y \cdot\left(\nu_{1} g\right)^{\beta}-C-e_{P}-\left(\delta_{K}+n\right) K-u \psi R^{-\zeta}, \\
\dot{R} & =-u, \\
\dot{M} & =\gamma u-\mu(M-\kappa \widetilde{M})-\theta\left(\nu_{3} \cdot g\right)^{\phi},
\end{aligned}
$$




$$
\begin{aligned}
& \dot{b}=(\bar{r}-n) b-\left(1-\alpha_{1}-\alpha_{2}-\alpha_{3}\right) \cdot e_{P} . \\
& \dot{g}=\alpha_{1} e_{P}+i_{F}-\left(\delta_{g}+n\right) g
\end{aligned}
$$

The control vector is given by

$$
U=\left(C, e_{P}, u\right) \in \mathbb{R}^{3},
$$

where $C$ denotes consumption, $e_{P}$ is tax revenue, and $u$ is the quantity of the resource $R$ extracted each period.

The first dynamic $\dot{K}$ is the accumulation rate of private (green) capital $K$ that produces renewable energy and which drives output by the CES production function,

$$
Y(K, u):=A\left(A_{K} K+A_{u} u\right)^{\alpha}
$$

where $A$ is multifactor productivity, ${ }^{22} A_{K}$ and $A_{u}$ are eciency indices of private capital inputs $K$ and (non-renewable) fossil fuel energy $u$, respectively. In equation (13), private-sector output $Y$ is modified by the infrastructure s hare a llocated t o productivity enhancement $\nu_{1} g$, for $\nu_{1} \in[0,1]$. This public-private interaction generates total output as $Y\left(\nu_{1} g\right)^{\beta}$ from which the economy consumes $C$, pays taxes $e_{P}$, and is subject to physical $\delta_{K}$ and demographic $n$ depreciation. The exponent $\beta$ is the output elasticity of public infrastructure, $\nu_{1} g$. The last term in equation (13) is the opportunity cost of extracting the non-renewable resource $u$, where $\psi$ and $\zeta$ are the scale and shape parameters that tie the marginal cost of $u$ to the remaining stock of the resource a la Hotelling (1931).

Equation (14) indicates the stock of the non-renewable resource $R$, which depletes by $u$ units in each period. The non-renewable resource emits carbon dioxide and thus increases the atmospheric concentration of $\mathrm{CO}_{2}$ at the rate $\gamma$ in equation (15). The stable level of $\mathrm{CO}_{2}$ emissions is $\kappa>1$ of the pre-industrial level $\widetilde{M}$, which is naturally re-absorbed into the ecosystem (e.g., oceanic reservoirs) at rate $\mu$. The last term in equation (15) is the reduction of per-period emissions $\dot{M}$ due to the allocation of $0 \leq \nu_{3} \leq 1$ of infrastructure $g$ to mitigation projects.

The last two dynamics are the accumulation of debt $b$ and public capital $g$. In equation (16) public debt grows at the fixed interest $\mathrm{r}$ ate $\bar{r}$, a nd is s erviced $\mathrm{w}$ ith the s hare of tax revenue $e_{P}$ not allocated respectively to capital accumulation, $\alpha_{1}$, social transfers, $\alpha_{2}$, or administrative overhead, $\alpha_{3}>0$. Thus, $\alpha_{4} \equiv 1-\alpha_{1}-\alpha_{2}-\alpha_{3}$. Equation (17) states that the stock of public capital, or total infrastructure, evolves according to the allocated tax revenue stream $\alpha_{1} e_{P}$ and funds paid in from abroad, $i_{F}$ (it may represent donations from outside donors). For developed countries we may assume $i_{F}=0$, but as positive for many developing countries. Concerning private capital, $g$, depreciates by $\delta_{g}$ and is adjusted for population growth, $n$.

\footnotetext{
${ }^{22}$ Here the multi-factor productivity $A$ is taken as constant but it could be made time varying in order to capture the slow productivity decline as resulting from slow temperature increase.
} 
We assume throughout that the infrastructural allocations satisfy

$$
\nu_{k} \geq 0 \quad(k=1,2,3), \quad \nu_{1}+\nu_{2}+\nu_{3}=1 .
$$

In later analysis, we either choose fixed values of $\nu_{1}, \nu_{2}, \nu_{3}$ or we consider the allocations as additional optimization variables.

Using the state variable, $X \in \mathbb{R}^{5}$, and control variable, $U \in \mathbb{R}^{3}$, we write the dynamics (13)-(17) in compact form as

$$
\dot{X}(t)=f(X(t), U(t)), \quad X(0)=X_{0} .
$$

The initial state vector $X_{0}$ will be specified later. To this system we add the terminal constraint

$$
K(T)=K_{T} \geq 0
$$

the control constraint

$$
0 \leq u(t) \leq u_{\max }
$$

and the pure state constraint

$$
M(t) \leq M_{\max } \quad \forall t \in[0, T]
$$

The terminal constraint restricts the final level of the capital stock to a predetermined nonnegative value, the control constraint prescribes an upper bound for the extraction rate, and finally the state constraint places a cap on the total level of $\mathrm{CO}_{2}$ in the atmosphere in each period.

Let us now define the objective functional, the social welfare functional. We maximize the following functional over a given planning horizon $[0, T]$, where $T>0$ denotes the terminal time:

$$
W(T, X, U)=\int_{0}^{T} e^{-(\rho-n) t} \frac{\left(C\left(\alpha_{2} e_{P}\right)^{\eta}(M-\widetilde{M})^{-\epsilon}\left(\nu_{2} g\right)^{\omega}\right)^{1-\sigma}-1}{1-\sigma} d t .
$$

The felicity (utility) function in (25) is isoelastic with four input components all in per capita terms: (i) consumption $C$; (ii) the share $0 \leq \alpha_{2} \leq 1$ of tax revenue $e_{P}$ used for direct welfare enhancement (e.g., health care); (iii) atmospheric concentration of $\mathrm{CO}_{2} M$ above the pre-industrial level $\widetilde{M}$; and (iv) the share $0 \leq \nu_{2} \leq 1$ of infrastructure $g$ allocated to climate change adaptation. Restricting the exponents $\eta, \epsilon, \omega>0$ ensures social expenditures and adaptation are utility enhancing, and that carbon emissions directly reduce utility. This approach differs from other models that map emissions to temperature changes and then to reduced productivity-cum-output. We believe the direct disutility approach better captures the wide ranging impacts of climate change that may include health impacts, ecological loss 
and heightened uncertainty, in addition to reduced productivity which can show up in the term $A$. Finally, note that the discount factor adjusts for the population growth rate, $n$, from the pure discount rate, $\rho$, as all values are normalized by the population.

To summarize, our model gives rise to an optimal control problem $O C(p)$, where the social welfare, equation (25), is maximized subject to the dynamic constraints (21) and the terminal, control and state constraints (22)-(24). For the multi-phase model, this has to be augmented by an algorithm which solves phases of the model with different objective functions and state variables and specifications, see Maurer et al. (2018). 